\title{
Azimuthally Averaged Wind and Thermodynamic Structures of Tropical Cyclones in Global Climate Models and Their Sensitivity to Horizontal Resolution
}

\author{
Yumin Moon, ${ }^{a}$ Daehyun Kim, ${ }^{a}$ SuZana J. CAMARgo, ${ }^{b}$ Allison A. Wing, ${ }^{\mathrm{c}}$ AdAm H. Sobel,

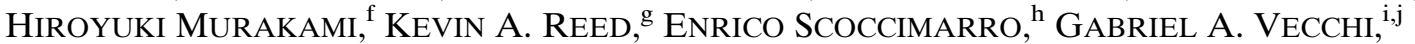 \\ MiCHAEL F. WeHNER, ${ }^{k}$ COLIN M. ZARZYCKI, ${ }^{1}$ AND Ming ZHAO ${ }^{f}$

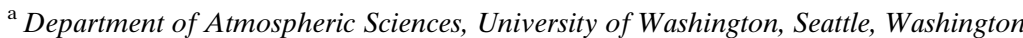 \\ ${ }^{\mathrm{b}}$ Lamont-Doherty Earth Observatory, Columbia University, Palisades, New York \\ ${ }^{\mathrm{c}}$ Department of Earth, Ocean, and Atmospheric Science, Florida State University, Tallahassee, Florida \\ d Department of Applied Physics and Applied Mathematics, Columbia University, New York, New York \\ ${ }^{\mathrm{e}}$ Department of Earth and Environmental Sciences, Columbia University, New York, New York \\ ${ }^{\mathrm{f}}$ NOAA/Geophysical Fluid Dynamics Laboratory, Princeton, New Jersey \\ ${ }^{\mathrm{g}}$ School of Marine and Atmospheric Sciences, Stony Brook University, State University of New York, \\ Stony Brook, New York \\ ${ }^{\mathrm{h}}$ Fondazione Centro Euro-Mediterraneo sui Cambiamenti Climatici, Bologna, Italy \\ ${ }^{\mathrm{i}}$ Geosciences Department, Princeton University, Princeton, New Jersey \\ ${ }^{\mathrm{j}}$ Princeton Environmental Institute, Princeton University, Princeton, New Jersey \\ ${ }^{\mathrm{k}}$ Lawrence Berkeley National Laboratory, Berkeley, California \\ ${ }^{1}$ Department of Meteorology and Atmospheric Science, Pennsylvania State University, University Park, Pennsylvania
}

(Manuscript received 5 March 2019, in final form 29 October 2019)

\begin{abstract}
Characteristics of tropical cyclones (TCs) in global climate models (GCMs) are known to be influenced by details of the model configurations, including horizontal resolution and parameterization schemes. Understanding model-to-model differences in TC characteristics is a prerequisite for reducing uncertainty in future TC activity projections by GCMs. This study performs a process-level examination of TC structures in eight GCM simulations that span a range of horizontal resolutions from $1^{\circ}$ to $0.25^{\circ}$. A recently developed set of process-oriented diagnostics is used to examine the azimuthally averaged wind and thermodynamic structures of the GCM-simulated TCs. Results indicate that the inner-core wind structures of simulated TCs are more strongly constrained by the horizontal resolutions of the models than are the thermodynamic structures of those TCs. As expected, the structures of TC circulations become more realistic with smaller horizontal grid spacing, such that the radii of maximum wind (RMW) become smaller, and the maximum vertical velocities occur off the center. However, the RMWs are still too large, especially at higher intensities, and there are rising motions occurring at the storm centers, inconsistently with observations. The distributions of precipitation, moisture, and radiative and surface turbulent heat fluxes around TCs are diverse, even across models with similar horizontal resolutions. At the same horizontal resolution, models that produce greater rainfall in the inner-core regions tend to simulate stronger TCs. When TCs are weak, the radial gradient of net column radiative flux convergence is comparable to that of surface turbulent heat fluxes, emphasizing the importance of cloud-radiative feedbacks during the early developmental phases of TCs.
\end{abstract}

\section{Introduction}

Since early pioneering studies noted the presence of tropical cyclone-like vortices in global climate model (GCM) simulations (e.g., Manabe et al. 1970; Bengtsson et al. 1982; Broccoli and Manabe 1990), GCMs have been used to provide helpful insights into global tropical

Corresponding author: Yumin Moon, yum102@atmos.uw.edu cyclone (TC) activity across multiple time scales from subseasonal to climate change [see Camargo and Wing (2016) for a comprehensive overview of TC simulations in GCMs]. Continuing advances in computational power and better numerical methods have made it more feasible in recent years to study TCs with high-resolution GCM simulations that have horizontal grid spacings of $0.5^{\circ}$ or less (e.g., Zhao et al. 2009; Murakami and Sugi 2010; Manganello et al. 2012; Murakami et al. 2012a; 
Shaevitz et al. 2014; Wehner et al. 2014; Zarzycki and Jablonowski 2014; Vecchi et al. 2014; Lim et al. 2015; Murakami et al. 2015; Reed et al. 2015; Roberts et al. 2015; Harris et al. 2016; Yamada et al. 2017; Scoccimarro et al. 2017; Roberts et al. 2018; Vecchi et al. 2019).

A known benefit of increasing horizontal resolution in GCM TC modeling is that models with smaller horizontal grid spacings tend to more frequently produce intense storms than do their lower-resolution counterparts (e.g., Bengtsson et al. 1995; Shen et al. 2006; Bengtsson et al. 2007; Caron et al. 2011; Manganello et al. 2012; Murakami et al. 2012a, 2015; Wehner et al. 2015). This relationship between horizontal resolution and simulated TC intensity indicates that it is important to represent smaller-scale processes in order to be able to simulate intense storms. Indeed, many previous modeling studies have examined the sensitivity of TC wind structures to horizontal resolution and shown that the structures of tangential and radial winds around the TC center become more realistic as horizontal grid spacings become smaller. In particular, the radii of maximum wind (RMWs) of the simulated TCs decrease with decreasing grid size (e.g., Manganello et al. 2012; Roberts et al. 2015).

However, a significant model-to-model difference in TC intensity has also been noted in recent studies that have examined TCs simulated with grid spacings smaller than $0.5^{\circ}$ (e.g., Shaevitz et al. 2014; Roberts et al. 2015). This suggests that the horizontal grid spacing of a GCM simulation may not be the only factor that exerts a strong influence over its TC simulation. In many cases, the large intermodel intensity spread could not be explained by differences in the simulated large-scale environmental fields that appear to be important for TC genesis and intensification in the observations (e.g., Kim et al. 2018; Camargo et al. 2019, manuscript submitted to J. Climate; Vecchi et al. 2019), as found earlier in lower-resolution models (Camargo et al. 2007); the sensitivity of pre-TC synoptic variability may help better understand TC sensitivity (e.g., Li et al. 2010; Vecchi et al. 2019). These findings indicate that differences in the model-simulated TC structures, which are in turn driven by model differences, are plausibly responsible for the intermodel spread in TC intensity distributions. The intensities of GCM-simulated TCs have been found to be sensitive to details of model configuration that can directly influence TC dynamics, such as the cumulus parameterization (e.g., Reed and Jablonowski 2011a; Kim et al. 2012; Murakami et al. 2012b; Stan 2012; Zhao et al. 2012; Lim et al. 2015), dynamical core (e.g., Zhao et al. 2012; Reed et al. 2015), and ocean-atmosphere coupling grid (Zarzycki et al. 2016), which all support this hypothesis.
To evaluate the relative influences of horizontal resolution and other model details on the intensities of GCM-simulated TCs, it is necessary to perform a systematic examination of TC wind and thermodynamic structures and their relationships with TC intensity among multiple models with different resolutions. The constraint of TC circulation structures by horizontal grid spacing of the GCM simulations has been examined before, typically with the most intense TC snapshots produced in the simulations (e.g., Manganello et al. 2012; Roberts et al. 2015). However, the degree to which simulated TC thermodynamic structures are constrained by horizontal resolution and model configurations has received less attention. Understanding the large intermodel spread among the models with comparable horizontal resolution would also require an evaluation of TC thermodynamic structures that are not fully constrained by the resolved TC wind structures. To the best of our knowledge, such sensitivity of thermodynamic structures of TCs to horizontal resolution has not been systematically explored.

Recently, Kim et al. (2018) introduced a set of process-oriented diagnostics that examine azimuthally averaged thermodynamic and dynamic TC fields. These process-oriented diagnostics evaluate the model representations of physical processes that influence TC intensity and offer insights that could be used to improve the parameterization features that are critical to TC processes. Kim et al. (2018) examined three $0.5^{\circ} \mathrm{GCM}$ simulations and found that the GCM that produced the strongest TCs also had the greatest precipitation-thus the greatest diabatic heating-near the TC center. This strongest-TC-producing GCM simulation also exhibited the greatest sensitivity of convection to moisture and the greatest contrast in free-tropospheric relative humidity and in surface heat fluxes between the inner and outer regions of TCs. These results illustrated that moistureconvection coupling and surface heat flux feedbacks are critical processes that control TC intensity in GCM simulations.

The current study utilizes the Kim et al. (2018) process-oriented TC diagnostics to examine TC structures in eight GCM simulations that have horizontal resolutions ranging from $1^{\circ}$ to $0.25^{\circ}$. Specifically, we ask the following questions:

- To what degree are the TC thermodynamic structures, including radiative and surface turbulent heat fluxes around TCs, constrained by horizontal resolution?

- Is the relationship between TC intensity and rainfall in the TC inner-core regions, found in Kim et al. (2018) in models with $0.5^{\circ}$ resolution, also applicable to 
TABLE 1. A summary of 8 GCM simulations analyzed in this study. The CAM5se simulation contains only tropical cyclones that form in the $0.25^{\circ}$ domain over the North Atlantic (NATL) region.

\begin{tabular}{|c|c|c|c|c|c|}
\hline $\begin{array}{l}\text { Simulation name } \\
\text { (short name) }\end{array}$ & $\begin{array}{l}\text { Horizontal } \\
\text { resolution }\end{array}$ & $\begin{array}{l}\text { Vertical } \\
\text { levels }\end{array}$ & $\begin{array}{l}\text { Simulation } \\
\text { years }\end{array}$ & $\begin{array}{l}\text { Ocean } \\
\text { coupling }\end{array}$ & Deep convection physics \\
\hline NCAR CAM5 SE (CAM5se) & $0.25^{\circ}$ NATL only & 30 & 1992-99 & No & Zhang and McFarlane (1995) \\
\hline NCAR CAM5 FV (CAM5fv) & $0.25^{\circ}$ & 30 & 1996-97 & No & Zhang and McFarlane (1995) \\
\hline CMCC CM2 (CMCC) & $0.25^{\circ}$ & 30 & $1958-59$ & Yes & Zhang and McFarlane (1995) \\
\hline GFDL AM2.5 (AM2.5) & $0.5^{\circ}$ & 32 & $1984-85$ & No & Relaxed Arakawa-Schubert \\
\hline GFDL FLOR (FLOR) & $0.5^{\circ}$ & 32 & $1984-85$ & Yes & Relaxed Arakawa-Schubert \\
\hline GFDL HiRAM (HiRAM) & $0.5^{\circ}$ & 32 & $1984-85$ & No & $\begin{array}{l}\text { Bretherton et al. (2004) with } \\
\text { modifications }\end{array}$ \\
\hline $\begin{array}{l}\text { MDTF NCAR CAM5 } \\
\text { (NCARts) }\end{array}$ & $1^{\circ}$ & 30 & 1990-94 & No & Zhang and McFarlane (1995) \\
\hline $\begin{array}{l}\text { MDTF GFDL AM4d } \\
\text { (GFDLts) }\end{array}$ & $1^{\circ}$ & 32 & $2008-12$ & No & $\begin{array}{l}\text { A double-plume model of } \\
\text { Zhao et al. }(2018 \mathrm{a}, \mathrm{b})\end{array}$ \\
\hline
\end{tabular}

models with finer horizontal grid spacings and among models with different horizontal resolutions?

- How robust is the role of cloud-radiation feedbacks across models with different horizontal resolutions?

The last question is motivated by recent modeling studies of tropical cyclogenesis in an idealized radiativeconvective equilibrium configuration (Wing et al. 2016). A period of enhanced convection associated with increased tropospheric water vapor and clouds, or a period of suppressed convection and decreased water vapor and clouds, alters the radiation budget at the surface and at the top of the atmosphere (TOA). The net radiative cooling of the atmosphere is enhanced in the area of suppressed convection and reduced in the moist, cloudy area of enhanced convection (i.e., an anomalous heating). In the tropics, where the horizontal temperature gradient is small and diabatic heating/ cooling is balanced mostly by adiabatic cooling/ heating associated with large-scale vertical motion (Charney 1963; Sobel et al. 2001), this anomalous heating from the cloud-radiation interaction fosters further development of convection in the same area by inducing an upward motion and horizontal moisture convergence associated with it. Wing et al. (2016) found that the longwave-cloud feedbacks are at least as important as the surface flux feedbacks during tropical cyclogenesis. Their mechanism denial experiment, in which the radiative heating rates were horizontally homogenized, showed that removing the longwave radiation-cloud feedback could significantly delay the onset of TC genesis.

The rest of the paper is organized as follows. Section 2 describes the eight GCM simulations examined in this study. Section 3 presents an analysis of azimuthally averaged structures of TCs simulated by the GCM experiments. Section 4 discusses a relationship between the inner-core rainfall and intensification likelihood.
A summary of the results and conclusions is provided in section 5 .

\section{GCM simulations}

This study examines TCs in eight GCM simulations. They can be grouped into three subsets, based on the horizontal grid spacings used in the simulations $-0.25^{\circ}$, $0.5^{\circ}$, and $1.0^{\circ}$ resolution. Table 1 provides a summary of the simulations examined in this study. We analyze TCs in 6-hourly slices of the GCM simulations. We focus on the azimuthally averaged structures of TCs, since TCs can be considered in the lowest order as axisymmetric vortices (e.g., Anthes 1982; Emanuel 1986, 2019). Azimuthal averages in this study are computed using $5-\mathrm{km}$ radial increments out to $r=1000 \mathrm{~km}$ from the TC center at pressure levels from 1000 to $50 \mathrm{hPa}$ with $25-\mathrm{hPa}$ increments. Wind, temperature, and moisture fields are taken from instantaneous model output every $6 \mathrm{~h}$ (e.g., 0000, 0600, 1200, and 1800 UTC). Precipitation, surface fluxes and radiative fluxes are from the average of the two consecutive 6-h time-averaged model outputs (i.e., a 12-h period) centered at the analysis time. Only TCs located within $25^{\circ}$ of the equator are considered for the analysis, and therefore subtropical storms or extratropical transitions of TCs are, at least for the most part, excluded. We also exclude TC snapshots that occur after their lifetime maximum intensity. Since the focus of this study is azimuthally averaged structures of TCs, we use the maximum azimuthally averaged surface (i.e., 10-m) wind speed to measure TC intensity.

\section{a. $0.25^{\circ}$ simulations}

We include three GCM simulations at $0.25^{\circ}$ horizontal resolution. Two of them are from versions of the atmosphere-only NCAR-DOE Community Atmospheric Model (CAM), version 5 (Neale et al. 2012), using two 
different dynamical cores-finite volume (FV; Lin 2004) and spectral element (SE; Dennis et al. 2012). Hereafter, they will be referred to as the CAM5fv and CAM5se simulations, respectively. The CAM5fv simulation uses a globally uniform $0.25^{\circ}$ horizontal grid spacing (e.g., Wehner et al. 2014), but the CAM5se simulation uses a variable-resolution horizontal grid, with $0.25^{\circ}$ grid only over the North Atlantic region and $1^{\circ}$ resolution elsewhere (e.g., Zarzycki and Jablonowski 2014; Zarzycki et al. 2017). Only TCs in the high-resolution $0.25^{\circ}$ grid over the North Atlantic region are examined in the CAM5se analysis. Both CAM5se and CAM5fv simulations have 30 vertical levels with the model top near $2 \mathrm{hPa}$. The CAM5fv and CAM5se simulations use the same CAM5 physics parameterization suite, including the Zhang-McFarlane deep convection (Zhang and McFarlane 1995), Park and Bretherton shallow convection (Park and Bretherton 2009), moist turbulence (Bretherton and Park 2009), and radiation (Mlawer et al. 1997; Iacono et al. 2008) schemes. The prescribed SST and sea ice boundary datasets are from Hurrell et al. (2008). The primary difference between the CAM5se and CAM5fv simulations lies in the dynamical cores, which have been shown to influence the simulation of TC activity (Reed and Jablonowski 2012; Reed et al. 2015). The CAM5se and CAM5fv simulations are performed for 1992-99 and 1996-97, respectively. Both the CAM5fv and CAM5se model simulations have been successfully used to study TCs in the past (e.g., Reed and Jablonowski 2011a; Shaevitz et al. 2014; Zarzycki and Jablonowski 2014; Reed et al. 2015; Wehner et al. 2015; Zarzycki 2016; Reed et al. 2019).

The other $0.25^{\circ}$ simulation is performed with the Fondazione Centro Euro-Mediterraneo sui Cambiamenti Climatici (CMCC) Climate Model, version 2 (CMCCCM2-VHR; Fogli and Iovino 2014; Scoccimarro et al. 2017; Cherchi et al. 2019). Its atmospheric component is the NCAR-DOE CAM, version 4 (e.g., Neale et al. 2010, 2013), that uses a globally uniform $0.25^{\circ}$ horizontal grid spacing and 30 vertical levels. Its ocean component is the NEMO ocean general circulation model, version 3.6 (Madec et al. 2008), that has the $0.25^{\circ}$ horizontal resolution and 50 levels in the vertical, with 22 levels representing the upper $100 \mathrm{~m}$ of the ocean. Hereafter, this will be referred to as the CMCC simulation. The CMCC simulation covers two years under fixed 1950 radiative forcing conditions.

\section{b. $0.5^{\circ}$ simulations}

The three $0.5^{\circ}$-resolution simulations examined in this study are the same that were recently analyzed in Kim et al. (2018). Two of the three $0.5^{\circ}$ simulations are from atmosphere-only GCMs: the Geophysical Fluid Dynamics Laboratory Atmospheric Model, version 2.5 (AM2.5;
Delworth et al. 2012), and High Resolution Atmospheric Model (HiRAM; Zhao et al. 2009). The other simulation is from a coupled atmosphere-ocean GCM: The Forecast-Oriented Low Ocean Resolution (FLOR; Vecchi et al. 2014) version of Coupled Model 2.5 (CM2.5; Delworth et al. 2012). The atmospheric components of the AM2.5 and FLOR models are identical. All three models use the same NOAA Geophysical Fluid Dynamics Laboratory (GFDL) finite volume dynamical core on a cubed sphere horizontal grid (Putman and Lin 2007) but have different physics parameterizations and ocean models. The AM2.5 and FLOR models use a relaxed ArakawaSchubert deep convection scheme (Moorthi and Suarez 1992), while the HiRAM model uses a shallow convection scheme of Bretherton et al. (2004) that has been modified to simulate both deep and shallow clouds (Zhao et al. 2009, 2012). Further details of the AM2.5, FLOR, and HiRAM models can be found in Delworth et al. (2012), Vecchi et al. (2014), and Zhao et al. (2009), respectively. All three models have the identical 32 vertical levels, and simulations are performed for two years between 1984 and 1985.

\section{c. $1.0^{\circ}$ simulations}

There are two $1^{\circ}$-resolution time-slice simulations whose outputs are made available for the NOAA Model Diagnostics Task Force (MDTF) project-the NCAR CAM 5.3 model and a developmental version of the GFDL AM4 model [referred to as AM4d below; see Zhao et al. (2018a,b) for the documentation of GFDL AM4]. Both models are atmosphere-only GCMs, so the simulations are AMIP type, with prescribed sea surface temperature and sea ice as lower boundary conditions. The NCAR CAM5 model has 30 vertical levels, and the GFDL AM4d model has 32 vertical levels. The NCAR CAM5 and GFDL AM4d simulations are performed for 1990-94 and 2008-12, respectively. Hereafter, the MDTF NCAR CAM, version 5.3 (Neale et al. 2012), and GFDL AM4d model simulations will be referred to as the NCARts and GFDLts.

\section{d. TC tracking algorithms and quality-control processes}

The center positions of TCs in the simulations are provided by the TC tracking algorithms selected for the simulations, which are different among the simulations. The $0.25^{\circ}$ CAM5se simulation uses the TempestExtremes tracker (Ullrich and Zarzycki 2017; Zarzycki et al. 2017), and the $0.25^{\circ} \mathrm{CAM} 5 \mathrm{fv}$ simulation uses the TC tracking algorithm from Zhao et al. (2009). The tracking algorithms from the Camargo and Zebiak (2002) are used for TCs in the $0.25^{\circ} \mathrm{CMCC}$ and the $1^{\circ}$ simulations. Three 
$0.5^{\circ}$ GFDL simulations use the tracking algorithm developed by Harris et al. (2016), as implemented in Murakami et al. (2015). These tracking algorithms typically search for a local minimum of sea level pressure that is collocated with a local maximum of $850-\mathrm{hPa}$ cyclonic vertical vorticity and positive temperature anomalies aloft (i.e., warm core).

The main differences between them are the definitions of the warm-core temperature anomalies and the minimum threshold values of maximum $850-\mathrm{hPa}$ cyclonic vertical vorticity and maximum surface wind speed used to define TCs. For example, the Zhao et al. (2009) algorithm uses the minimum 850-hPa cyclonic vorticity threshold of $1.6 \times 10^{-4} \mathrm{~s}^{-1}$ in the $0.25^{\circ} \mathrm{CAM} 5 \mathrm{fv}$ simulation. The $0.5^{\circ}$ GFDL simulations are tracked with $1.5 \times 10^{-4} \mathrm{~s}^{-1}$ as the minimum $850-\mathrm{hPa}$ cyclonic vorticity threshold with the Harris et al. (2016) and Murakami et al. (2015) algorithms. The Camargo and Zebiak (2002) algorithm for the $0.25^{\circ} \mathrm{CMCC}$ and the $1^{\circ}$ simulations uses a minimum 850 -hPa cyclonic vorticity threshold that is determined from an analysis of its probability distribution computed during the peak TC seasons in individual TC basins. The TempestExtremes tracker for the $0.25^{\circ} \mathrm{CAM} 5$ se simulation searches for a local minimum in sea level pressure only with the corresponding warm-core check aloft. Only TC snapshots whose maximum surface wind speeds reach at least $17.5 \mathrm{~m} \mathrm{~s}^{-1}$ [i.e., $34 \mathrm{kt}\left(1 \mathrm{kt} \approx 0.5144 \mathrm{~m} \mathrm{~s}^{-1}\right)$ ] are included in the analysis. All TC tracking algorithms include only snapshots of TCs that persisted at least 48 (e.g., CAM5se, CMCC, GFDLts, and NCARts simulations) or $72 \mathrm{~h}$ (e.g., CAM5fv, AM2.5, FLOR, and HiRAM simulations).

There exists a possibility that different threshold values used in the tracking algorithms could result in different TC center positions. To evaluate this possibility, a subset of TC snapshots from the simulations has been visually inspected, and we found that almost all of the snapshots have their TC centers defined at local minima in sea level pressure (not shown). This means that the sensitivity of the TC center position to the choice of tracking algorithm is likely minimal. To further ensure that the tracking algorithms correctly identify the TC center, we checked and discarded TC snapshots that have anticyclonic azimuthally averaged $850-\mathrm{hPa}$ tangential winds at $r=10$ and $15 \mathrm{~km}$ from the center or have the negative radial gradient of azimuthally averaged $850-\mathrm{hPa}$ tangential winds. TC snapshots typically show cyclonic tangential winds and positive radial gradient of tangential velocity just off the center (e.g., Willoughby and Rahn 2004; Mallen et al. 2005). Since some of the analyzed GCM simulations do not include surface wind fields as part of the available model outputs, the maximum azimuthally averaged surface wind speed is calculated with the lowest model level wind field extrapolated to the $10-\mathrm{m}$ level, assuming a log profile with open sea conditions (e.g., Garratt 1992; Zarzycki and Jablonowski 2014).

\section{Azimuthally averaged storm structures}

\section{a. Intensity distributions}

Figure 1a shows intensity distributions of all TC snapshots tracked in the GCM simulations. Since the focus of this study is on azimuthally averaged structures of TCs, we use the maximum azimuthally averaged surface wind speed to measure TC intensity. TC wind speeds are binned into $3 \mathrm{~m} \mathrm{~s}^{-1}$ intervals, with Figs. 1b-d showing only $0.25^{\circ}, 0.5^{\circ}$, and $1.0^{\circ}$ simulations. Also shown in Fig. 1a as a reference is the International Best Track Archive for Climate Stewardship (IBTrACS; Knapp et al. 2010), version 3, dataset between 1984 and 2012, which covers many of the periods simulated by the models examined in this study. The IBTrACS data from the National Hurricane Center are used for TCs in the North Atlantic and eastern Pacific regions, and the IBTrACS Joint Typhoon Warning Center data are used for the western Pacific, Indian Ocean, Australia, and South Pacific regions. As in the GCM simulations, only TC points located within $25^{\circ}$ of the equator are used in the IBTrACS calculation (plotted as the black line) in Fig. 1a. It is important to note that the IBTrACS intensities refer to the maximum sustained surface wind speed - without azimuthal averaging — while the maximum azimuthally averaged surface wind speed is used to measure TC intensity in the GCM simulations; the maximum azimuthally averaged wind speed is generally lower than the maximum sustained wind speed for the same given TC snapshots.

Two additional features in Fig. 1a need to be highlighted. As horizontal resolution increases (thus going from Fig. 1d to Fig. 1b), the peak of the intensity distribution curves tends to shift toward higher wind speeds, and the probabilities in the higher wind speed $\left(>30 \mathrm{~m} \mathrm{~s}^{-1}\right)$ tails increase. These features suggest that stronger TCs are more frequent in higher-resolution GCM simulations, as noted in many previous studies (e.g., Reed and Jablonowski 2011b; Manganello et al. 2012; Murakami et al. 2012a; Reed et al. 2012; Shaevitz et al. 2014; Wehner et al. 2015; Daloz et al. 2015). There are also considerable variations in intensity distributions even at similar horizontal resolutions. For example, the $0.5^{\circ}$ HiRAM intensity distribution in Fig. $1 \mathrm{c}$ has its peak at the same wind speed as do the other $0.5^{\circ}$ simulations, but with a greater frequency of occurrence in the higher wind speed $\left(>30 \mathrm{~m} \mathrm{~s}^{-1}\right)$ tail. The $0.25^{\circ}$ CAM5fv and CMCC intensity distributions in Fig. 1b have their 
(a) intensity distribution ( $3 \mathrm{~m} / \mathrm{s}$ bins)

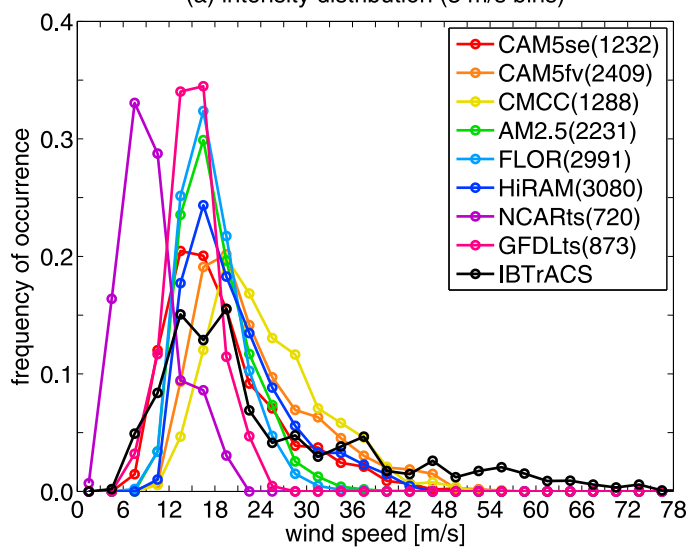

(c) 0.5 deg. intensity distribuion

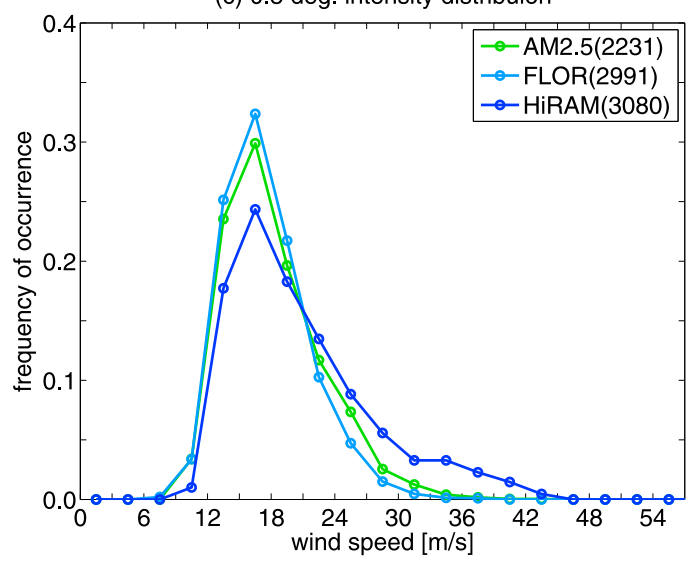

(b) 0.25 deg. intensity distribution

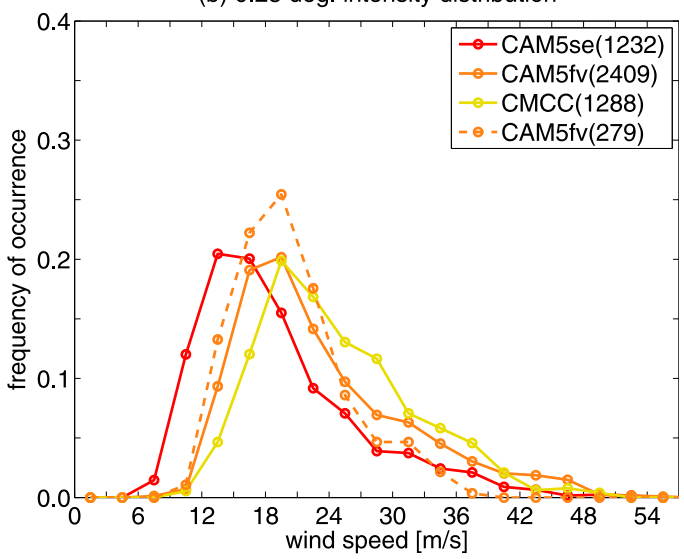

(d) 1.0 deg. intensity distribution

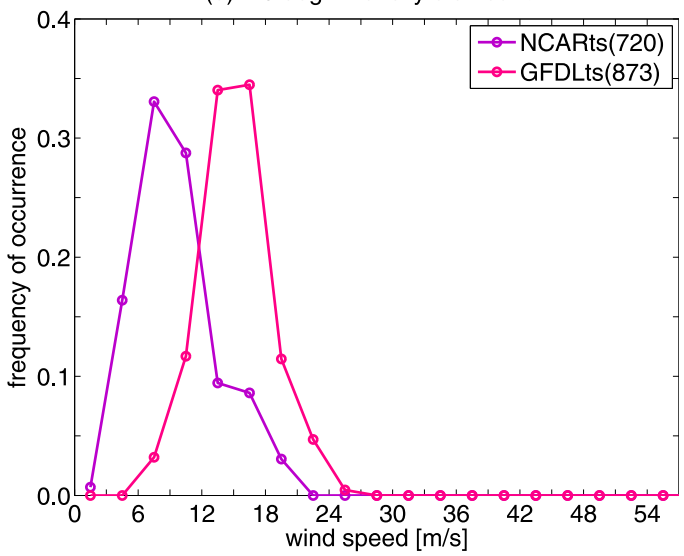

FIG. 1. (a) TC intensity distribution curves of all GCM simulations examined in this study. (b)-(d) As in (a), but only showing $0.25^{\circ}, 0.5^{\circ}$, and $1^{\circ}$ simulations. The total number of individual snapshots for each simulation is shown in the legends. Plotted as the thick black solid line in (a) is the best track data between 1984 and 2012. The best track datasets from the National Hurricane Center and Joint Typhoon Warning Center are used in (a). The best track intensity is the maximum sustained surface wind speed, but the maximum azimuthally averaged surface wind speed is used to measure TC intensity in the GCM- simulated TCs. Dashed orange line in (b) is for TCs in the CAM5fv simulation over the North Atlantic region only.

peaks at higher wind speeds than does the $0.25^{\circ}$ CAM5se simulation, but the CAM5fv simulation has a greater frequency of occurrence in the higher wind speed $\left(>45 \mathrm{~m} \mathrm{~s}^{-1}\right)$ tail. It is important to reiterate here that the CAM5se snapshots are only from the North Atlantic region that is covered by the $0.25^{\circ}$-resolution grid, so that the CAM5se is missing western North Pacific typhoons that are on average stronger than the North Atlantic hurricanes. If the CAM5fv intensity distribution is calculated only for TCs in the North Atlantic region as in the CAM5se simulation (see dashed orange line in Fig. 1b), the CAM5se simulation (red line in Fig. 1b) produces intense TCs more frequently than the CAM5fv simulation (e.g., Reed et al. 2015; see section 4). In addition, it is possible that the different threshold values used in the tracking algorithms for the $0.25^{\circ}$ simulations could influence the lower wind speed tails of the intensity distributions, as the differences in the tracking schemes are more pronounced at lower storm intensities (e.g., Horn et al. 2014).

\section{b. Three-dimensional wind fields}

Figure 2 shows radius-pressure plots of azimuthally averaged tangential and radial winds for TCs that have intensities of $18-21 \mathrm{~m} \mathrm{~s}^{-1}$ in all simulations, while Fig. 3 shows radius-pressure plots of azimuthally averaged omega pressure velocity and warm-core temperature anomalies for TCs at the same intensity interval. Warmcore temperature anomalies are defined here as deviations from the environmental mean, which in turn is defined as the average of a TC-centered square $2000 \mathrm{~km}$ long on a side but with the innermost square $1000 \mathrm{~km}$ long on a side removed. The wind fields depicted in 

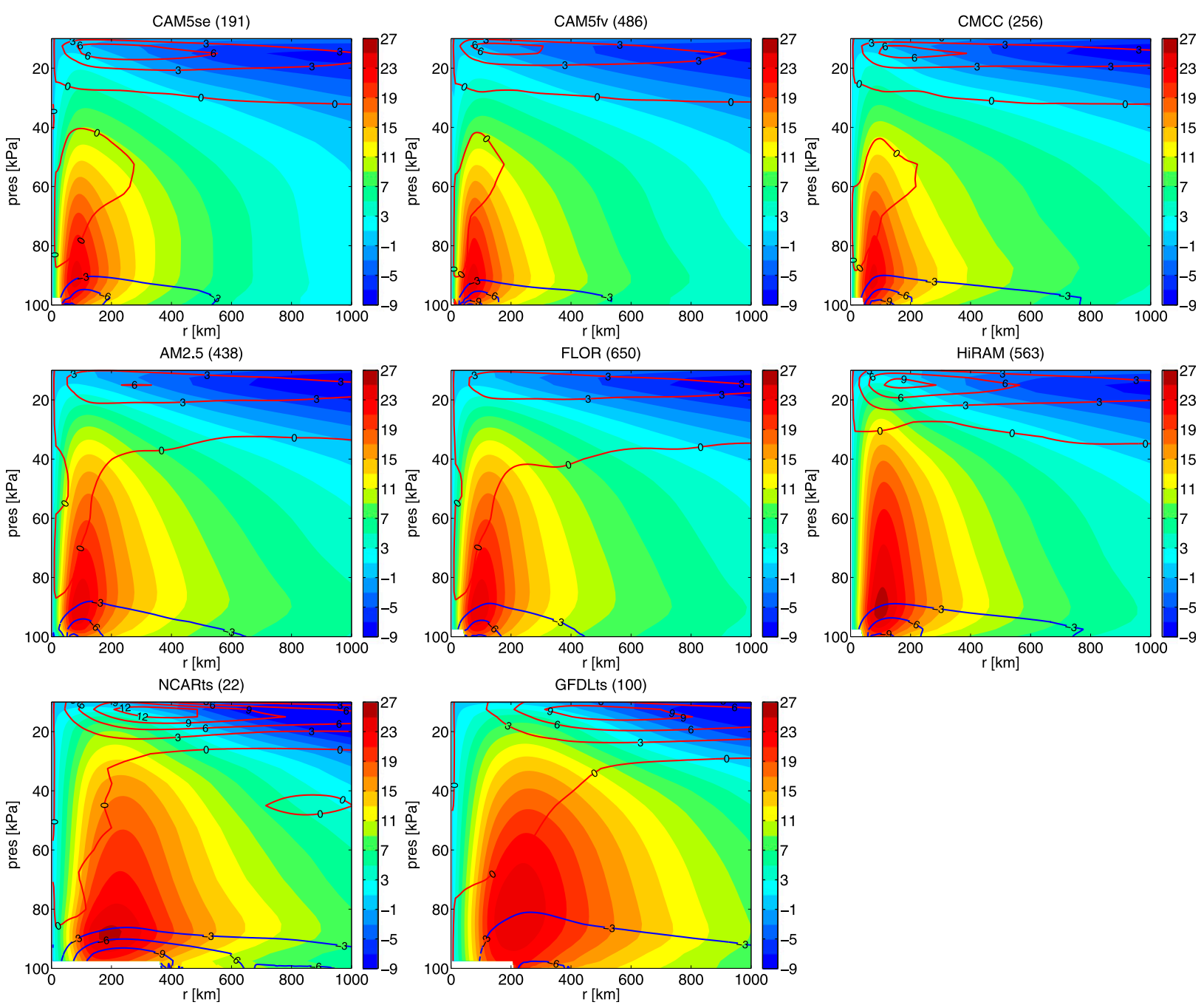

FIG. 2. Radius-pressure plots of azimuthally averaged tangential velocity (color shading) and radial velocity (lines), for TC snapshots that have the intensity of $18-21 \mathrm{~m} \mathrm{~s}^{-1}$. The top, middle, and bottom rows are the $0.25^{\circ}, 0.5^{\circ}$, and $1^{\circ}$ simulations, respectively. Units are $\mathrm{m} \mathrm{s}^{-1}$. Numbers in parentheses show the number of snapshots.

Figs. 2 and 3 share many similarities with observed TCs (e.g., Frank 1977; Anthes 1982). GCM-simulated TCs have cyclonic tangential winds that have their RMWs occurring off center. Tangential winds decay with increasing radius away from the RMW and also with decreasing pressure in the free troposphere, which suggest that these vortices are warm-cored systems. Tangential winds increase with increasing height between the surface and the 900-hPa level.

Examining the radial winds in Fig. 2 together with the pressure velocities in Fig. 3 indicates that there are overturning secondary circulations that have low-level radial inflow toward the center and upper-level radial outflow away from the center, with rising motions occurring between them near the center. These threedimensional wind fields resemble the primary (i.e., cyclonic tangential winds) and secondary (i.e., "in-upout" structures of radial and vertical winds) circulations associated with TCs in observations (e.g., Frank 1977; Anthes 1982). TC composites in all simulations have pronounced positive warm-core temperature anomalies near the center. However, models exhibit the maximum warm-core temperature anomalies at different pressure levels at $18-21 \mathrm{~m} \mathrm{~s}^{-1}$, and the magnitude of the maximum warm-core anomalies does not appear to show horizontal resolution dependency. The magnitude of the maximum azimuthally averaged tangential wind speed at the top of the boundary layer around $900 \mathrm{hPa}$ does not show much of horizontal resolution dependency either.

A noteworthy feature of the GCM-simulated storms is in the structure of the near-center vertical velocity fields depicted in Fig. 3. Previous observational studies have 

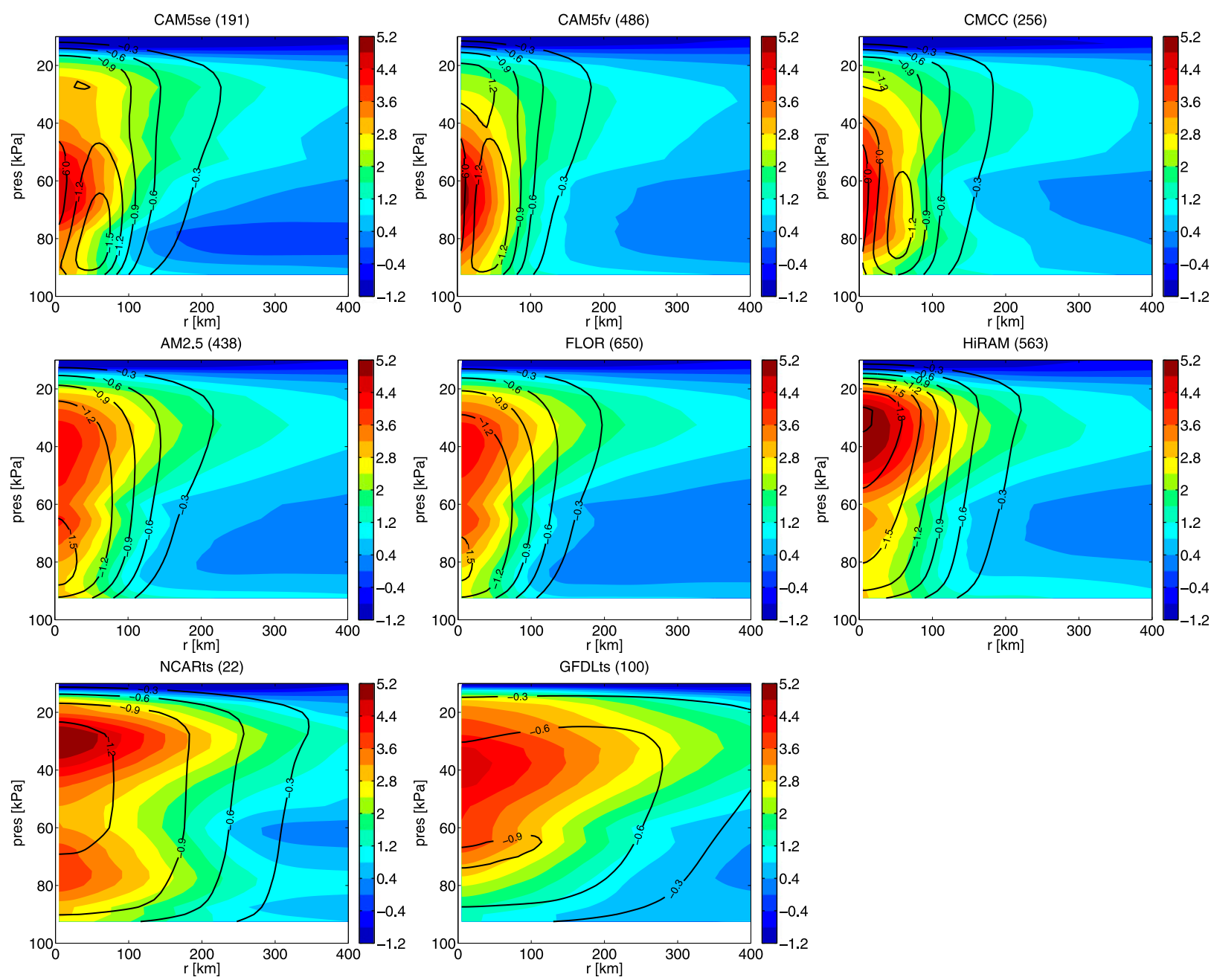

FIG. 3. As in Fig. 2, but for warm-core temperature anomalies (color shading) and pressure velocity (lines). Negative pressure velocity

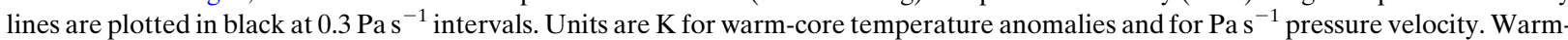
core temperature anomalies are departures from the environment, which is the average of a TC-centered 2000-km square but excluding its inner 1000-km square area.

shown that well-developed TCs have their maximum ascent off the center in the eyewall regions (e.g., Shea and Gray 1973; Gray and Shea 1973; Frank 1977; Jorgensen 1984). However, Fig. 3 shows instead rising motions maximizing at the TC center in the $0.5^{\circ}$ and $1^{\circ}$ composites, in contrast to the observations. However, there are encouraging hints that smaller horizontal grid spacings lead to qualitatively better representations of vertical velocity near the TC center. The location of the peak upward motion (i.e., the most negative omega values) appears to move away from the center as horizontal resolution increases (i.e., going from the bottom to top panels in Fig. 3). All of the $0.25^{\circ}$ simulations in Fig. 3 have their maximum rising motions occurring off the center around $r=50 \mathrm{~km}$, in qualitative agreement with the observations. However, the peak magnitude of the upward vertical motion does not appear to increase monotonically with increasing horizontal resolution.

The azimuthally averaged three-dimensional wind structures of TCs in Fig. 2, especially the RMW and RMW-modulated structures, show resolution dependence in the inner-core regions. The RMWs in the azimuthally averaged tangential winds are located at about $r=200 \mathrm{~km}$ in the $1^{\circ}$ models but move radially inward to about $r=100 \mathrm{~km}$ in the $0.5^{\circ}$ models and $r=75 \mathrm{~km}$ in the $0.25^{\circ}$ models. However, despite this resolution dependence, the RMWs in all models are still greater than in the observations, although the RMWs in the $0.25^{\circ}$ composites are more comparable to those in the observations (e.g., Kimball and Mulekar 2004). The location of the maximum low-level radial inflow shows a similar trend with resolution. Upward vertical motions in the 

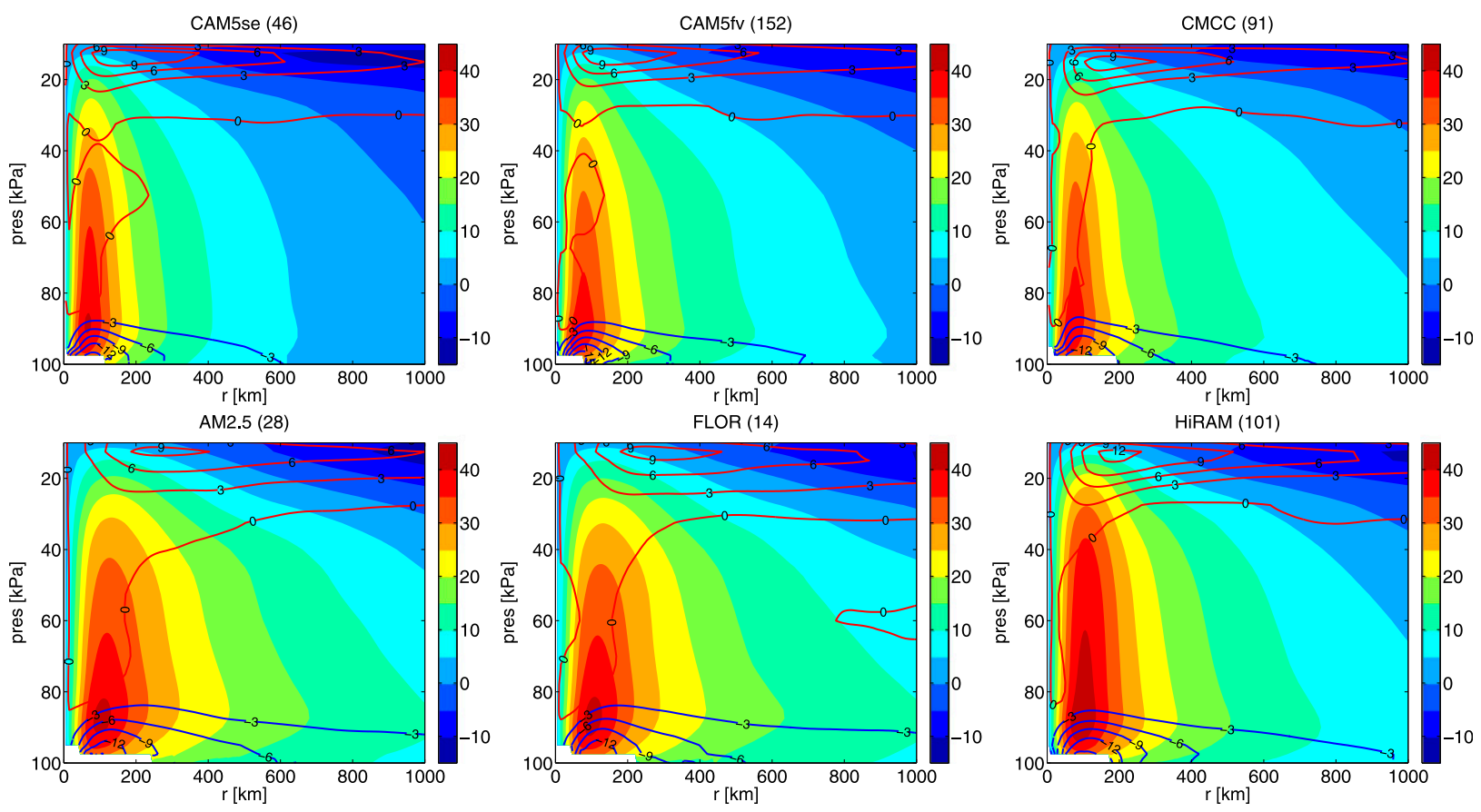

FIG. 4. As in Fig. 2, but for TC snapshots that have the intensity of $30-33 \mathrm{~m} \mathrm{~s}^{-1}$.

inner-core regions become narrower as horizontal resolution increases, which reflects the smaller RMWs in the higher-resolution simulations. That the TC inner-core wind structures become more compact with increasing horizontal resolution is consistent with previous studies (e.g., Reed and Jablonowski 2011c; Manganello et al. 2012; Reed and Chavas 2015; Roberts et al. 2015). While the RMWs are larger in GCM-simulated TCs, it is possible that they can still capture the appropriate radial and size structures given the simulated minimum central pressure and wind speed allowable by the horizontal grid spacing (Chavas et al. 2017).

Figures 4 and 5 show radius-pressure plots of azimuthally averaged three-dimensional wind and warmcore temperature anomalies structures for TCs that have intensity of $30-33 \mathrm{~m} \mathrm{~s}^{-1}$. Only the $0.25^{\circ}$ and $0.5^{\circ}$ simulations are shown because the $1^{\circ}$ simulations do not produce TCs at this intensity interval. The azimuthally averaged three-dimensional TC wind fields shown are similar to those in Figs. 2 and 3, except that the circulations are stronger. The primary cyclonic tangential winds are vertically deeper, and the overturning secondary circulations are stronger, with faster low-level inflow, upperlevel outflow, and upward motions near the center. The RMWs are located near $r=100 \mathrm{~km}$ and $70 \mathrm{~km}$ in the $0.5^{\circ}$ and $0.25^{\circ}$ simulations, values that are greater than those in the observations (e.g., Kimball and Mulekar 2004).

The peak updrafts in the $0.5^{\circ}$ AM2.5 and FLOR simulations are located off the center in the $30-33 \mathrm{~m} \mathrm{~s}^{-1}$ composites, as compared to being at the center in the weaker storms (cf. Figs. 3 and 5). The $0.5^{\circ}$ HiRAM TC composites still have their peak updrafts occurring at the center in Fig. 5, but they are located off the center at a higher intensity interval (e.g., $39-42 \mathrm{~m} \mathrm{~s}^{-1}$, not shown). The $0.25^{\circ}$ and $0.5^{\circ}$ composites do not show sinking motions near the TC center, even in the upper troposphere, in contrast to what is found in observations (e.g., Shea and Gray 1973; Gray and Shea 1973; Frank 1977; Jorgensen 1984). There are individual TC snapshots that do show sinking motions in the upper troposphere, but the frequency of such snapshots is low (less than $10 \%$ on average across the models, not shown). All models produce the strongest warm-core anomalies aloft between 200 and $400 \mathrm{hPa}$ at $30-33 \mathrm{~m} \mathrm{~s}^{-1}$, with some models (e.g., CAM5fv, AM2.5, and FLOR) showing vertically double-peaked structures. The magnitude of the maximum warm-core anomalies does not appear to depend on horizontal resolution. The RMWs, maximum lowlevel radial inflows, and peak upward motions are all located at smaller radii in the $0.25^{\circ}$ simulations than in the $0.5^{\circ} \mathrm{AM} 2.5$ and FLOR simulations in this intensity interval.

The above results indicate that the RMW and RMWmodulated wind structures in the TC inner-core regions have robust relationships to horizontal resolution. In the following two subsections, we examine the thermodynamic structures of TCs and their sensitivities to horizontal resolution. We are particularly interested in the 

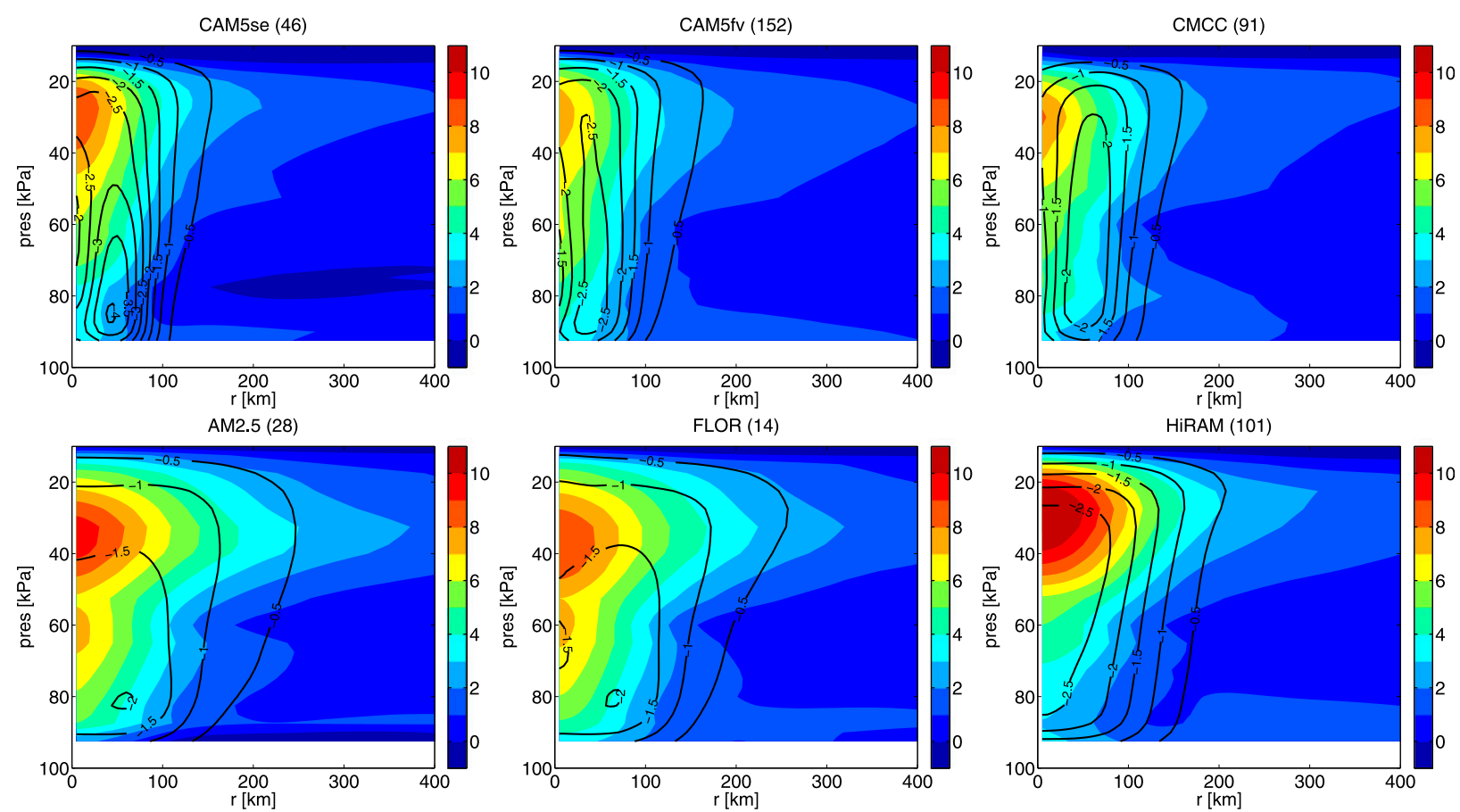

FIG. 5. As in Fig. 3, but for TC snapshots that have the intensity of $30-33 \mathrm{~m} \mathrm{~s}^{-1}$. Negative pressure velocity lines are plotted in black at $0.5 \mathrm{~Pa} \mathrm{~s}^{-1}$ intervals.

degree to which horizontal resolution constrains the TC thermodynamic structures.

\section{c. Rainfall and moisture}

Figure 6 shows azimuthally averaged rainfall rates for TCs in the 18-21 and $30-33 \mathrm{~m} \mathrm{~s}^{-1}$ intensity intervals. As expected, the rainfall rates are highest in the TC inner-core regions in all composites. Lower-resolution TC composites appear to have broader inner-core rainfall maxima than do their higher-resolution counterparts, consistent with the greater RMWs in the lower-resolution GCM simulations (e.g., Figs. 2 and 4). However, decreasing horizontal grid spacing from $1^{\circ}$ to $0.25^{\circ}$ does not lead to a monotonic increase in the magnitude of the peak inner-core rainfall rates. In fact, all three $0.5^{\circ}$ simulations and one $1^{\circ}$ simulation (NCARts) produce higher peak rainfall rates than do the $0.25^{\circ}$ simulations at $18-21 \mathrm{~m} \mathrm{~s}^{-1}$, and the $0.5^{\circ} \mathrm{HiRAM}$ simulation produces the greater inner-core rainfall than the $0.25^{\circ}$ simulations at $30-33 \mathrm{~m} \mathrm{~s}^{-1}$. It is possible that larger TCs in lower-resolution GCM simulations may need more energy to sustain themselves by inducing more precipitation (thus more diabatic heating). It is interesting to note that the $0.25^{\circ}$ simulations have the peak rainfall occurring off the center, but the $0.5^{\circ}$ and $1^{\circ}$ simulations show rainfall rates that monotonically decrease with increasing radius from the center, consistent with the vertical velocity fields depicted in Figs. 3 and 5.
To better understand the intermodel differences in the distributions of rainfall rates in and near TCs, a few moisture fields that could provide insights into the intermodel differences in the rainfall rates are examined. Figure 7 shows azimuthally averaged precipitable water in the $100-850 \mathrm{hPa}$ layer. The free-tropospheric precipitable water is greatest near the TC center in all composites. At $18-21 \mathrm{~m} \mathrm{~s}^{-1}$, the free-tropospheric precipitable water is comparable in the $0.25^{\circ}$ and $0.5^{\circ}$ simulations, but, interestingly, the $1^{\circ}$ simulations produce the greatest free-tropospheric precipitable water. In the $0.25^{\circ}$ and $0.5^{\circ}$ simulations, the free-tropospheric precipitable water near the center increases with intensity. Figure 8 shows azimuthally averaged column relative humidity $(\mathrm{CRH})$ in the same free-tropospheric $(100$ $850 \mathrm{hPa}$ ) layer. At $18-21 \mathrm{~m} \mathrm{~s}^{-1}$, the $\mathrm{CRH}$ reaches its maximum value off the center and then decreases with radius, except in the HiRAM and NCARts simulations, which show monotonic decreases from the center. The $0.25^{\circ}$ and $0.5^{\circ} \mathrm{TC}$ composites have comparable CRH values, and the $1^{\circ}$ NCARts TCs have the highest CRH at this intensity. In the $0.25^{\circ}$ simulations, the free-tropospheric column becomes more saturated at $30-33 \mathrm{~m} \mathrm{~s}^{-1}$, but now the CAM5se simulation shows a monotonically decreasing $\mathrm{CRH}$ profile with radius from the center. This occurs because relatively dry midtropospheric air at the center of the CAM5se TCs is less evident at $30-33 \mathrm{~m} \mathrm{~s}^{-1}$ than at $18-21 \mathrm{~m} \mathrm{~s}^{-1}$ (cf. Figs. 9 and 10 ). The free-tropospheric 
(a) rain rate @ $18-21 \mathrm{~m} / \mathrm{s}$

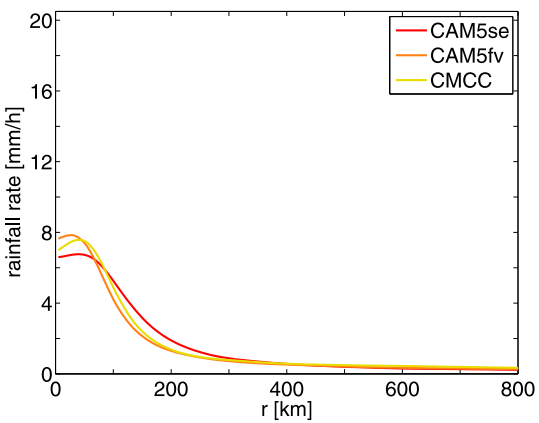

(d) rain rate @ $30-33 \mathrm{~m} / \mathrm{s}$

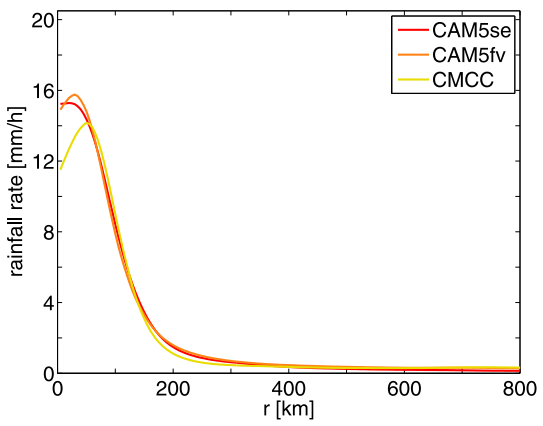

(b) rain rate @ $18-21 \mathrm{~m} / \mathrm{s}$

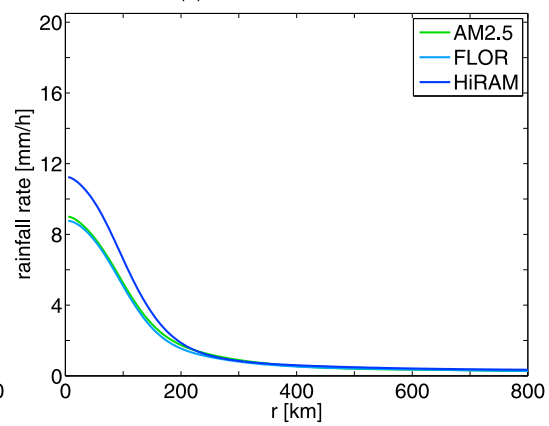

(e) rain rate @ $30-33 \mathrm{~m} / \mathrm{s}$

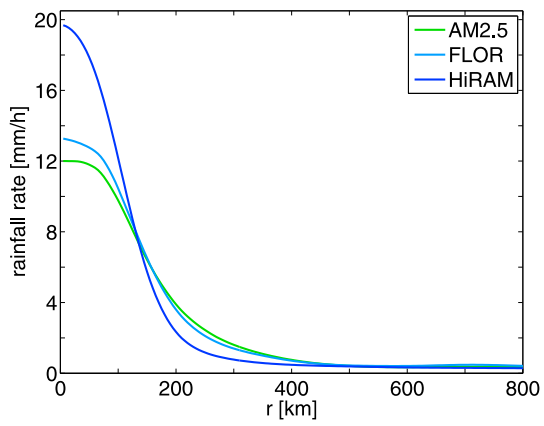

FIG. 6. Azimuthally averaged rainfall rates for TC snapshots that have the intensity of (a)-(c) 18-21 and (d),(e) $30-33 \mathrm{~m} \mathrm{~s}^{-1}$ for the (left) $0.25^{\circ}$, (middle) $0.5^{\circ}$, and (right) $1^{\circ}$ simulations.

precipitable water and relative humidity do not appear to show systematic variations with horizontal resolution, except that their inner-core structures are more compact with smaller horizontal grid spacing, which likely reflects the smaller RMWs in the higher-resolution TC simulations. The highest inner-core rainfall rates do not appear to be associated with the greater amount of the freetropospheric precipitable water or CRH. Perhaps the (a) 100-850 hPa precip. water @ 18-21 m/s

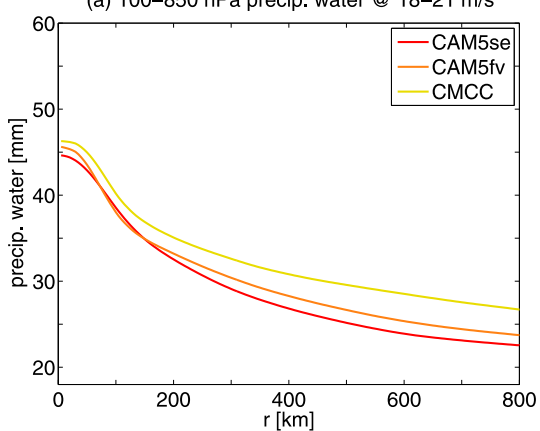

(d) 100-850 hPa precip. water @ 30-33 m/s

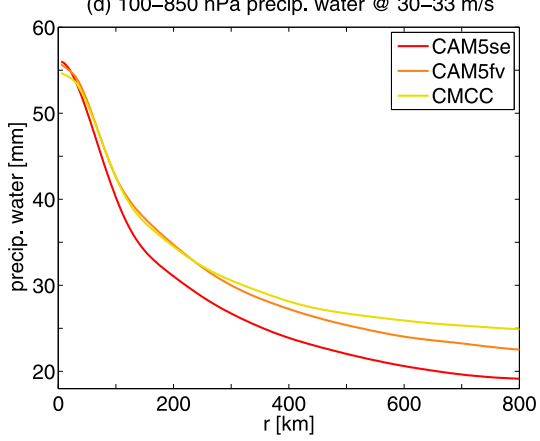

(b) 100-850 hPa precip. water @ 18-21 m/s

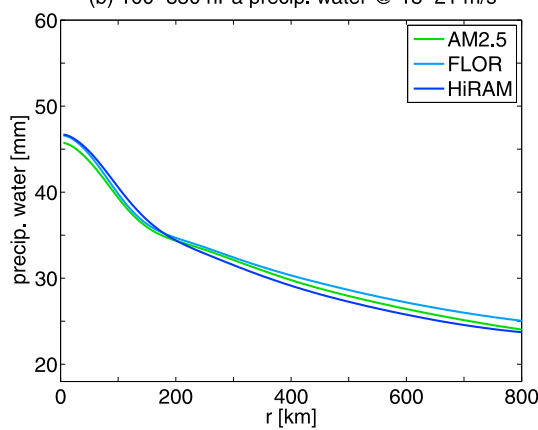

(e) 100-850 hPa precip.water @ 30-33 m/s

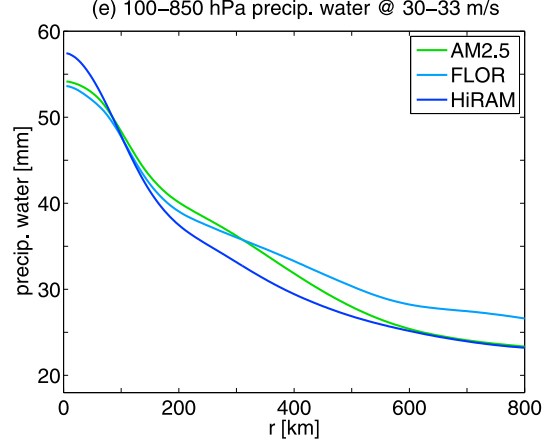

(c) 100-850 hPa precip. water @ 18-21 m/s

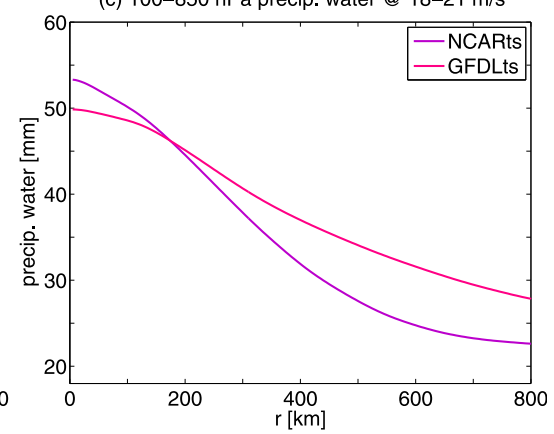

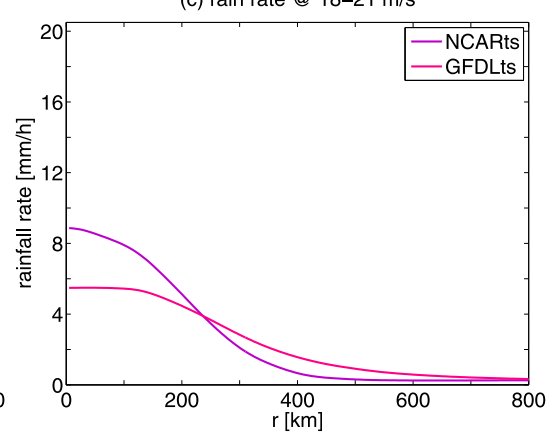

$$
+\infty
$$


(a) 100-850 hPa column RH @ 18-21 m/s

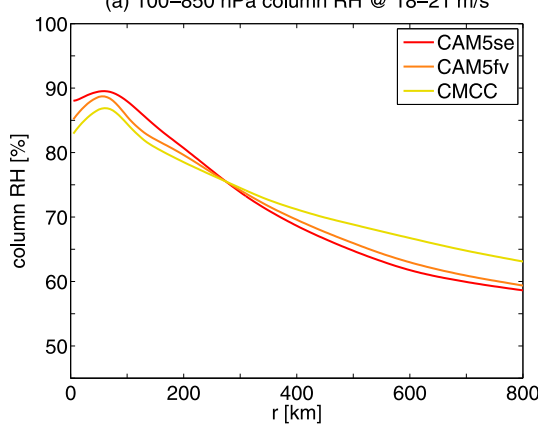

(d) $100-850 \mathrm{hPa}$ column RH @ 30-33 m/s

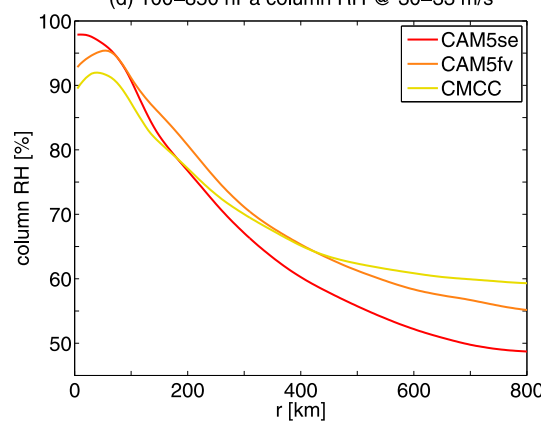

(b) 100-850 hPa column RH @ 18-21 m/s

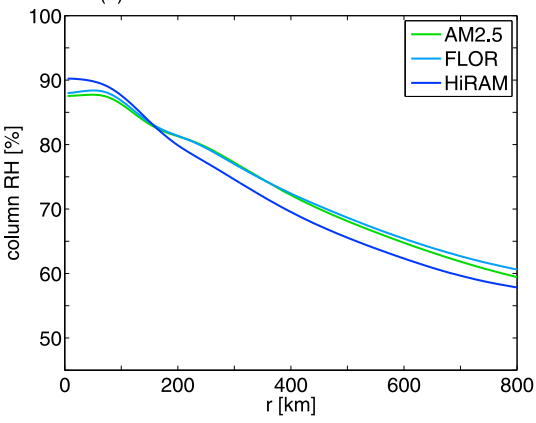

(e) $100-850 \mathrm{hPa}$ column RH @ 30-33 m/s

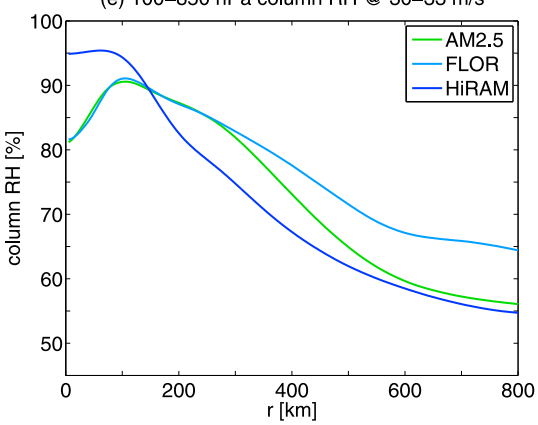

(c) 100-850 hPa column RH @ 18-21 m/s

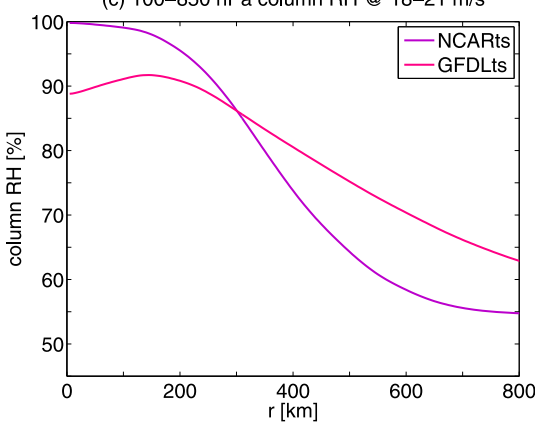

FIG. 8. Azimuthally averaged $100-850 \mathrm{hPa}$ column relative humidity for TC snapshots that have the intensity of (a)-(c) 18-21 and (d),(e) $30-33 \mathrm{~m} \mathrm{~s}^{-1}$ for the (left) $0.25^{\circ}$, (middle) $0.5^{\circ}$, and (right) $1^{\circ}$ simulations.

lack of systematic changes in many TC thermodynamic structures with horizontal resolution is not too surprising, given that this study examines a diverse set of GCM simulations.

\section{d. Surface and TOA moist enthalpy fluxes}

Figure 11 shows azimuthally averaged surface turbulent heat fluxes at the same intensity intervals as in Fig. 6. The maximum surface heat fluxes occur off the center, near the RMWs in their corresponding horizontal wind fields (cf. Figs. 2 and 4). Between the $0.25^{\circ}$ and $0.5^{\circ}$ simulations, the magnitude of the inner-core surface heat flux increases with decreasing horizontal grid spacing and also with increasing intensity. The radial gradient of the surface heat flux also increases with intensity. However, at $18-21 \mathrm{~m} \mathrm{~s}^{-1}$ the maximum surface heat flux in the $1^{\circ}$ NCARts is almost as high as that in the $0.25^{\circ} \mathrm{CAM} 5 \mathrm{se}$, which produces the greatest maximum in the surface heat flux among the simulations at that intensity interval. This suggests that increasing horizontal resolution does not necessarily lead to a monotonic increase in the magnitude of the maximum surface heat flux for all ranges of horizontal resolution. However, the location of the maximum surface heat flux moves radially inward with decreasing horizontal grid spacing due to the smaller RMWs. The surface heat flux far from the TC center does not appear to show systematic variations with either intensity or horizontal grid spacing.
It is interesting to note that the CMCC and FLOR TCs, both of which have interactive oceans, have weaker surface heat fluxes in the TC inner-core regions than do their similar-resolution counterparts, likely reflecting the TC wind stress-induced SST cooling (e.g., Price 1981; Zarzycki 2016; Scoccimarro et al. 2017).

Figure 12 shows azimuthally averaged net column radiative flux convergence at the same intensity intervals as in Fig. 6. Positive (or negative) net column radiative flux convergence means the column atmosphere is warming (or cooling). The net column radiative flux convergence is calculated as the difference between the TOA and surface net radiative fluxes. The NCARts simulation does not have all the necessary terms to compute the net column flux convergence and is omitted. The net column radiative flux convergence is greater near the storm center in all TC snapshots because of heating from the cloud-radiative effects. Some simulations (e.g., CMCC) show a small net positive column radiative flux convergence near the center, while some other simulations (e.g., AM2.5 and FLOR) have a small net negative column radiative flux convergence near the center. The negative radial gradient in the net column radiative flux convergence increases with intensity in the CAM5se, CAM5fv, and HiRAM simulations. The net column radiative flux convergence does not appear to show any substantial variations with horizontal resolution. 

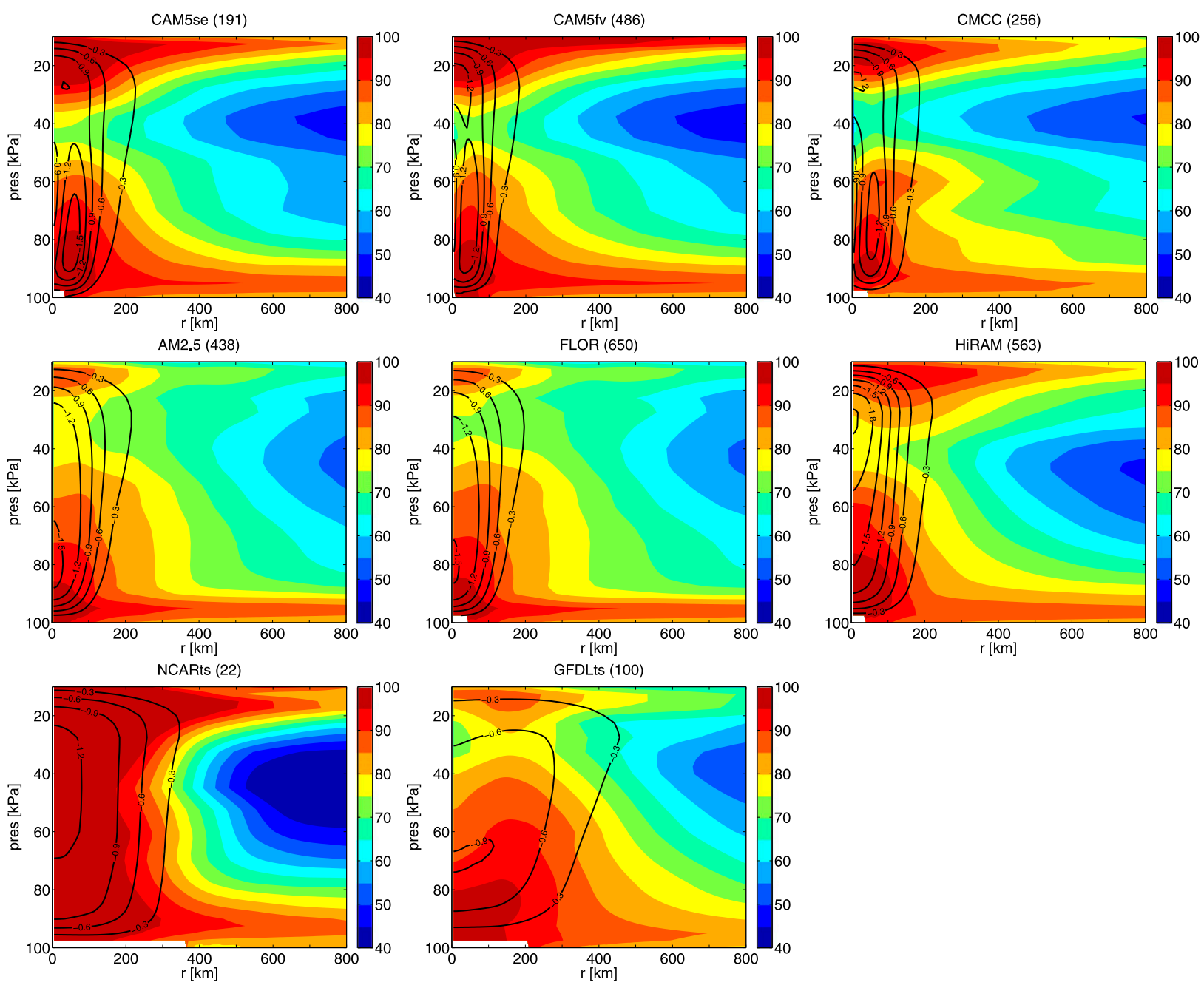

FIG. 9. As in Fig. 2, but for relative humidity (shading) and pressure velocity (lines). Negative lines are plotted in blue at 0.5 Pa s ${ }^{-1}$ intervals. Units are \% for relative humidity and $\mathrm{Pa} \mathrm{s}^{-1}$ for pressure velocity.

While the magnitude of the net column radiative flux convergence is smaller than that of the surface heat flux, the difference of the net column radiative flux convergence between $r=0 \mathrm{~km}$ and $800 \mathrm{~km}$ is comparable to that of the surface heat flux at $18-21 \mathrm{~m} \mathrm{~s}^{-1}$. The inner-toouter difference in the net column radiative flux convergence is $80-100 \mathrm{~W} \mathrm{~m}^{-2}$, while the difference in the surface heat flux is $50-200 \mathrm{~W} \mathrm{~m}^{-2}$. As TCs become stronger, the radial difference of the surface turbulent heat flux becomes larger than that of the net column radiative flux convergence. This indicates that at low intensity, the contributions of surface heat flux and radiative feedbacks are comparable, but at higher intensity, the surface heat flux feedbacks dominate. This strongly suggests that the cloud-radiative feedbacks that arise from a radial gradient of net column radiative flux convergence could play a significant role in the early developmental phases of TCs, consistent with the moist static energy budget analysis by Wing et al. (2016, 2019), as well as the results of Camargo and Sobel (2004) in much lower-resolution models.

\section{Inner-core rainfall and intensification}

Kim et al. (2018) examined the $0.5^{\circ}$ GFDL simulations and found that the HiRAM model simulated stronger TCs than the AM2.5 and FLOR models because the HiRAM TCs tended to produce a greater amount of rainfall-that is, diabatic heating —in the TC inner-core region. More diabatic heating near the center is considered favorable for further TC development and intensification. It has been hypothesized that the efficiency with which latent heating is able to generate the kinetic energy of the TC cyclonic rotational flow is greatest 

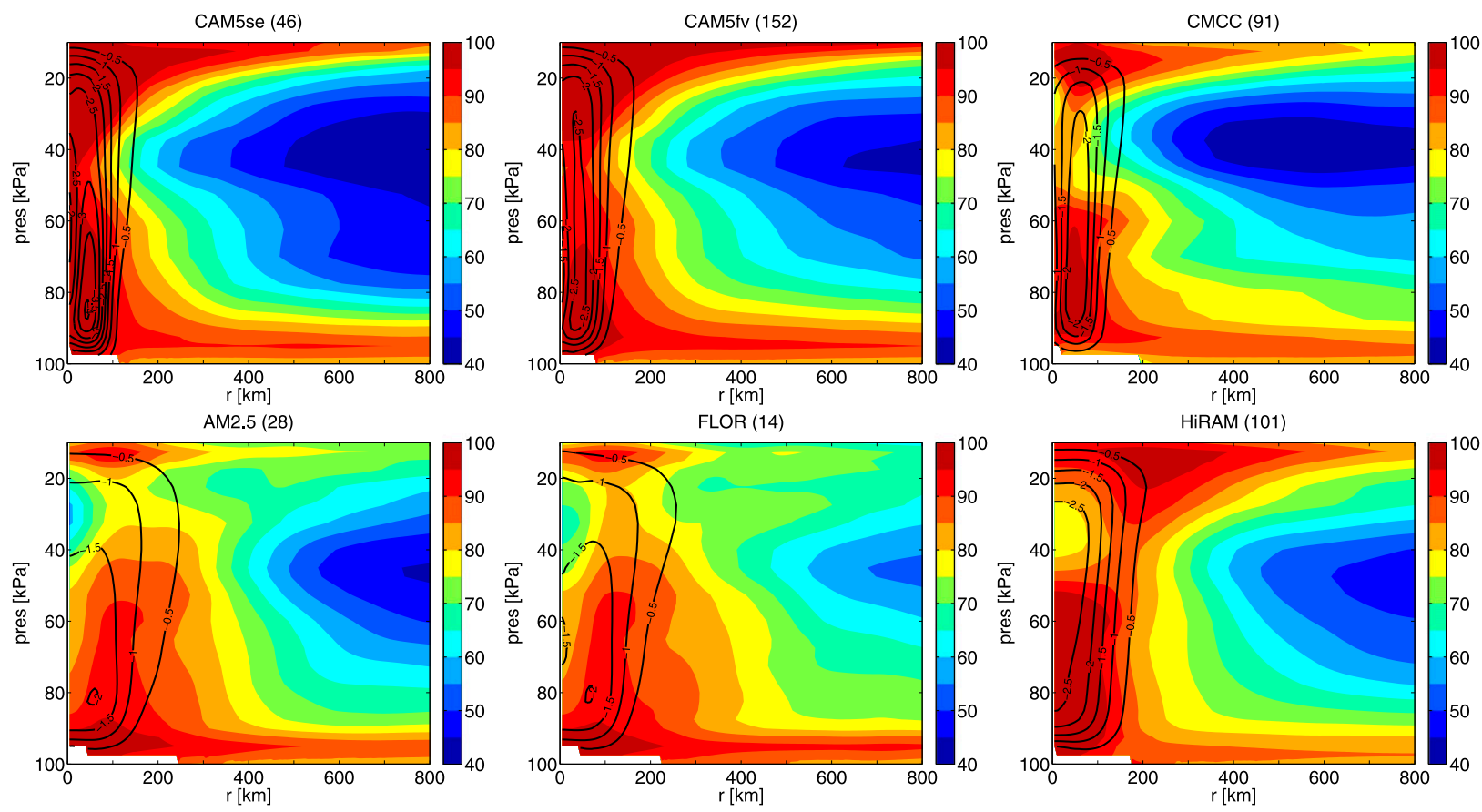

FIG. 10. As in Fig. 9, but for TC snapshots that have the intensity of $30-33 \mathrm{~m} \mathrm{~s}^{-1}$.

near the center, where inertial stability is higher (e.g., Schubert and Hack 1982; Shapiro and Willoughby 1982; Hack and Schubert 1986; Nolan et al. 2007). Now we evaluate this hypothesis with the CAM5se- and
CAM5fv-simulated TCs in the North Atlantic region (defined to be $5^{\circ}$ and $81^{\circ} \mathrm{W}$, based on the CAM5se grid structure shown in Fig. 1 of Zarzycki and Jablonowski 2014) during 1996-97, which is the overlapping period (a) surface heat flux @ 18-21 m/s
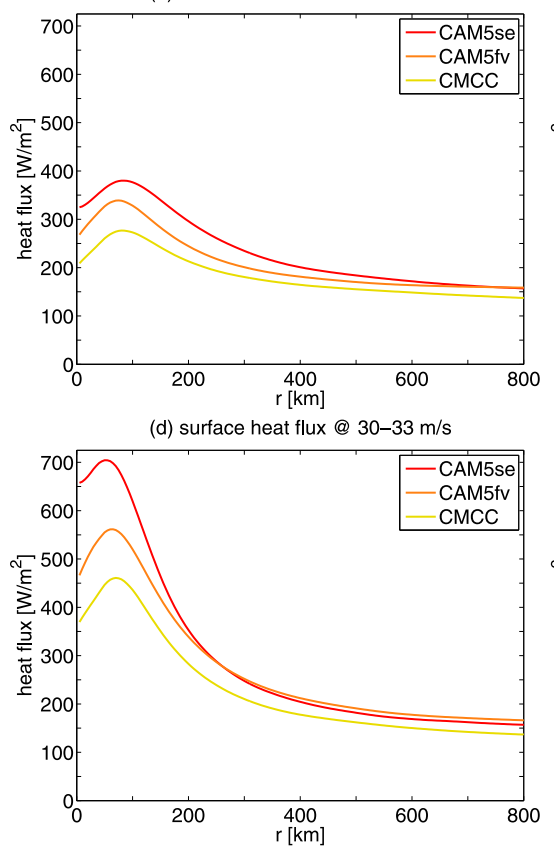

(b) surface heat flux @ 18-21 m/s

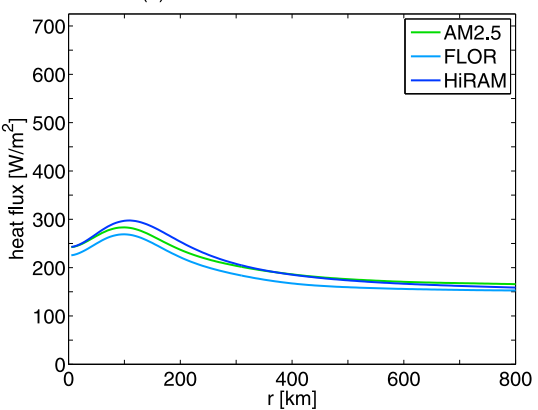

(e) surface heat flux @ $30-33 \mathrm{~m} / \mathrm{s}$

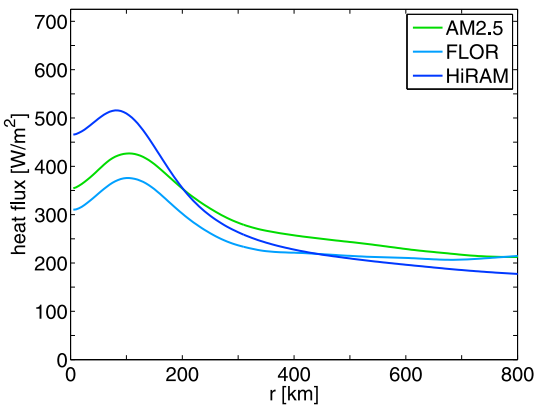

(c) surface heat flux @ 18-21 m/s

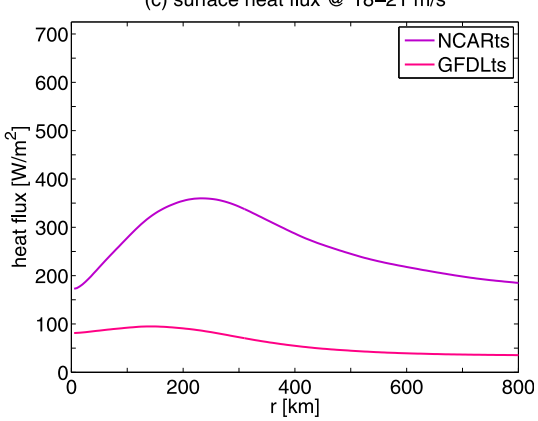

FIG. 11. Azimuthally averaged surface heat fluxes for TC snapshots that have the intensity of (a)-(c) $18-21$ and (d),(e) $30-33 \mathrm{~m} \mathrm{~s}{ }^{-1}$ for the (left) $0.25^{\circ}$, (middle) $0.5^{\circ}$, and (right) $1^{\circ}$ simulations. 

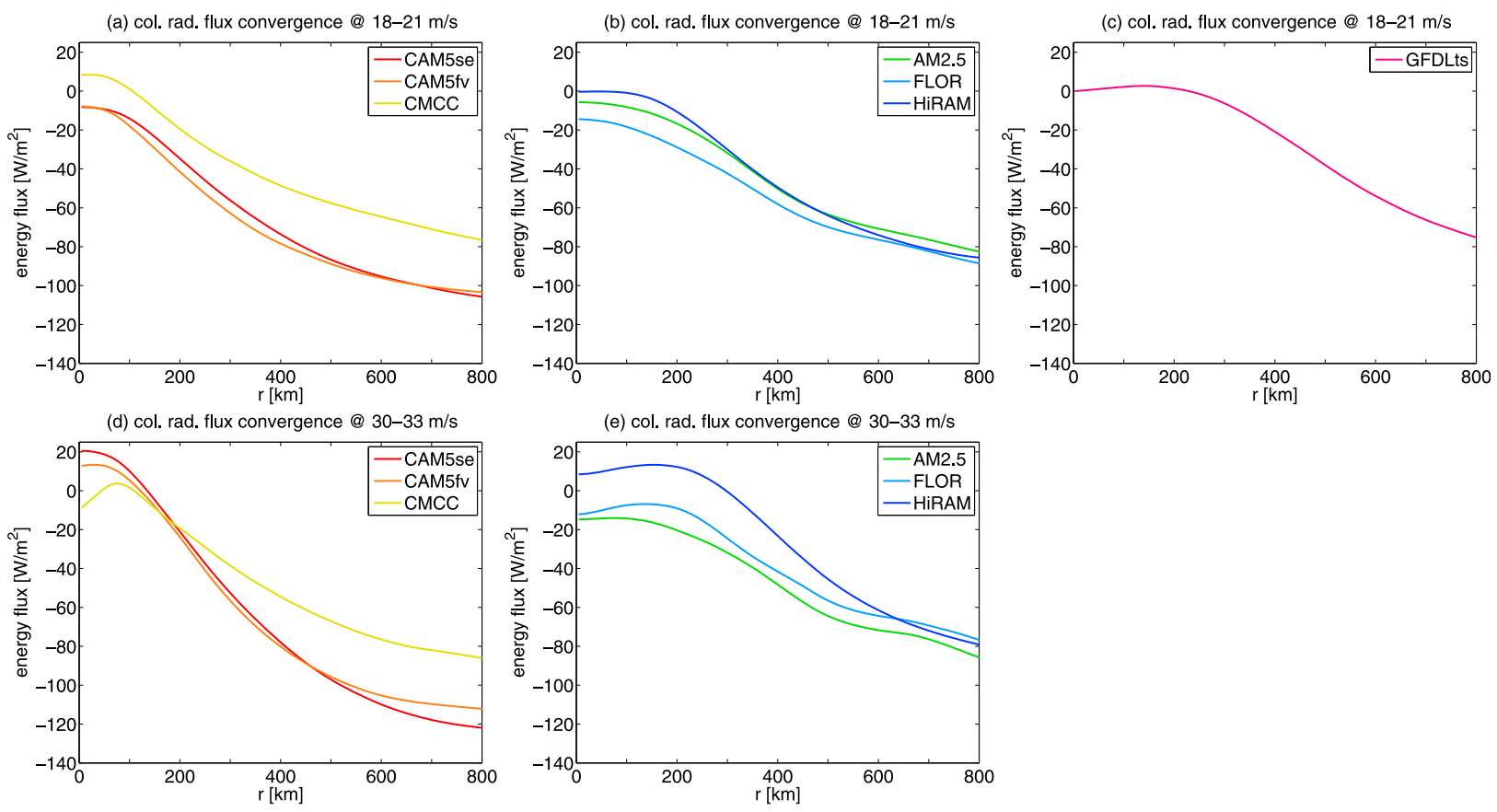

FIG. 12. Azimuthally averaged net column radiative flux convergence for TC snapshots that have the intensity of (a)-(c) 18-21 and (d),(e) $30-33 \mathrm{~m} \mathrm{~s}^{-1}$ for the (left) $0.25^{\circ}$, (middle) $0.5^{\circ}$, and (right) $1^{\circ}$ simulations.

between the two simulations. As discussed earlier, the main difference between the CAM5se and CAM5fv simulations is their dynamical cores (e.g., spectral element in CAM5se and finite volume in CAM5fv). Reed et al. (2015) previously found that the CAM5se simulations tended to produce stronger TCs than the CAM5fv simulations at $0.25^{\circ}$ resolution, although their intensity distributions show the peak at the same wind speed (see Fig. 3 of Reed et al. 2015).

Figure 13a shows intensity distributions for the 199697 North Atlantic TCs. The CAM5se and CAM5fv simulations produce similar intensity distributions, with the peaks occurring near $18-21 \mathrm{~m} \mathrm{~s}^{-1}$. However, the CAM5se simulation produces more intense TCs than does the CAM5fv simulation in the higher wind speed $\left(>30 \mathrm{~m} \mathrm{~s}^{-1}\right)$ tail, consistent with Reed et al. (2015). Figures $13 \mathrm{~b}$ and $13 \mathrm{c}$ show radius-pressure plots of azimuthally averaged radial and tangential winds of TCs that have intensity of $30-33 \mathrm{~m} \mathrm{~s}^{-1}$ in the simulations, and they look mostly similar. Azimuthally averaged radiuspressure plots at other intensity intervals do not reveal drastically different structures (not shown).

A notable structural difference between the simulations is found in the inner-core rainfall rates. Figure 13d shows the composite rainfall rates at $30-33 \mathrm{~m} \mathrm{~s}^{-1}$ in the CAM5se and CAM5fv simulations. The peak of the rainfall rates in the CAM5fv TCs is greater and located at smaller radii than in the CAM5se TCs. However, the
CAM5se rainfall rates decrease with radius at a slower rate than do those in CAM5fv, and this actually leads to a greater total area-averaged rainfall in the inner-core regions of the CAM5se TCs. The TC inner-core region is defined to be 2 times the RMW in the azimuthally averaged 850-hPa tangential winds (see the vertical solid lines in Figs. 13d,e). To illustrate this point, Fig. 13e shows the rainfall rates in Fig. 13d multiplied by the area of a $5-\mathrm{km}$ width annulus centered at the radial grid that is used to compute azimuthal averages. For example, the azimuthally averaged rainfall rate at $r=50 \mathrm{~km}$ is multiplied by an annulus whose outer and inner radii are 52.5 and $47.5 \mathrm{~km}$, respectively. Since the area of an annulus increases with radius [i.e., $\pi\left(R^{2}-r^{2}\right)$, where $R$ and $r$ are the outer and inner radii], the area-integrated rainfall radially outward of the peak rainfall in the CAM5se TCs is greater than in the CAM5fv TCs, and this overwhelms the greater areaintegrated rainfall closer to the center in the CAM5fv TCs. This results in a greater amount of the total areaaveraged rainfall, thus integrated diabatic heating, in the inner-core regions of the CAM5se TCs (see the colored bar graphs in Fig. 13d). More diabatic heating in the innercore regions provides more favorable conditions for the CAM5se TCs to intensify further.

The difference in the inner-core rainfall rates between the CAM5se TCs and CAM5fv TCs can be attributed to the difference in their surface heat fluxes. Figure 14a shows the composite total surface heat fluxes 

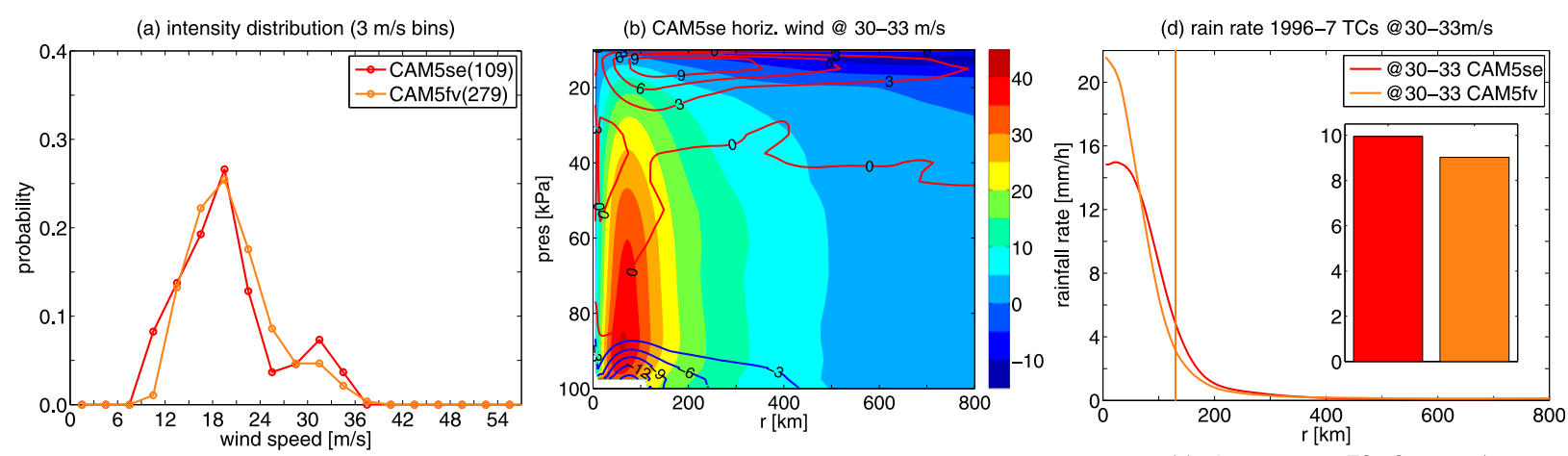

(c) CAM5fv horiz. wind @ $30-33 \mathrm{~m} / \mathrm{s}$
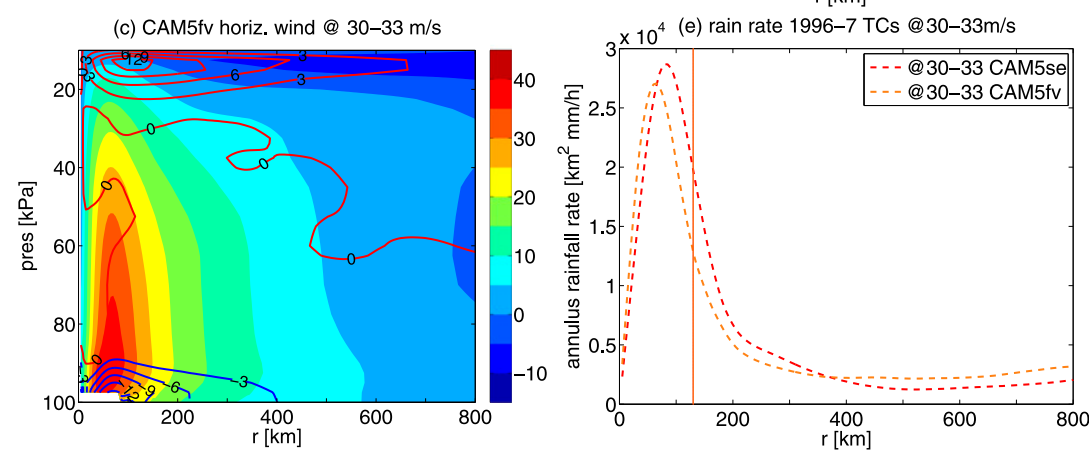

FIG. 13. (a) Intensity distributions of all TCs detected in the CAM5se and CAM5fv simulations over the North Atlantic during $1996-97$. (b),(c) Radius-pressure composite plots of azimuthally averaged tangential velocity (shading) and radial velocity (lines) of the CAM5se and CAM5fv TCs at 30-33 m s${ }^{-1}$. (d) Azimuthally averaged rainfall rates for TC snapshots that have the intensity of 30-33 m s${ }^{-1}$ for 199697 North Atlantic TCs in the CAM5se and CAM5fv simulations. The inset bar graphs in (d) show the amount of area-averaged rain rates in the TC inner-core region, which is defined to be 2 times the RMW in the azimuthally averaged $850-\mathrm{hPa}$ tangential winds $(850$-hPa RMW). (e) Azimuthally averaged rainfall rates in (d) multiplied with the area of a 5-km width annulus centered at the radial grid. Vertical solid lines in (d),(e) show the radially outer edges of the TC inner-core regions.

at $30-33 \mathrm{~m} \mathrm{~s}^{-1}$. The CAM5se TCs have substantially greater surface heat fluxes, especially in the inner-core region. The greater surface heat fluxes are mostly coming from the latent heat fluxes (Fig. 14b). Figure 14c shows the surface wind speed at the same intensity interval, and the CAM5fv TCs actually have slightly higher wind speeds than the CAM5se TCs. Figure 14d shows the difference between specific humidity at the lowest model level and saturation specific humidity of the underlying SST at the same intensity bin, and it indicates that the greater humidity difference at the airsea interface under the CAM5se TCs contributes more to the greater latent heat fluxes. Therefore, the tendency of the CAM5se simulation to keep the air-sea humidity difference greater leads to the greater latent (and total) heat flux in the TC inner-core region, which in turn leads to more rainfall and diabatic heating near the center and helps TCs intensify further (e.g., Schubert and Hack 1982; Shapiro and Willoughby 1982; Hack and Schubert 1986; Nolan et al. 2007). This is consistent with Wing et al. (2019), who found the CAM5se TCs have a stronger surface flux feedback in the inner-core regions than the CAM5fv TCs.
The results described in the preceding paragraphs indicate that the CAM5se model produces greater rainfall-thus more diabatic heating - in the TC innercore region and tends to simulate stronger TCs more frequently as a consequence. Kim et al. (2018) also found similar results: the HiRAM model produced greater inner-core rain rates than the other models in their ensemble and also simulated more intense TCs more frequently. The above results raise the question of whether this relationship would hold for a larger dataset. Figure 15 shows a scatterplot of the area-averaged innercore rainfall rates at $12-15 \mathrm{~m} \mathrm{~s}^{-1}$ versus the fraction of TCs intensifying from 12 to $18 \mathrm{~m} \mathrm{~s}^{-1}$ for all of the GCM simulations. The TC inner-core region is defined to be 2 times the RMW in the 850-hPa tangential winds as in Fig. 13. Diamonds, squares, and circles are used for the $0.25^{\circ}, 0.5^{\circ}$, and $1.0^{\circ}$ simulations. The scatterplot shows a clear positive correlation between the inner-core rainfall rates and intensification probability across almost all of the simulations. These high positive correlations are consistent with previous theoretical studies that found greater diabatic heating near the TC center to be favorable for TC intensification (e.g., Schubert and Hack 
(a) total heat flux 1996-7 TCs @ 30-33 m/s

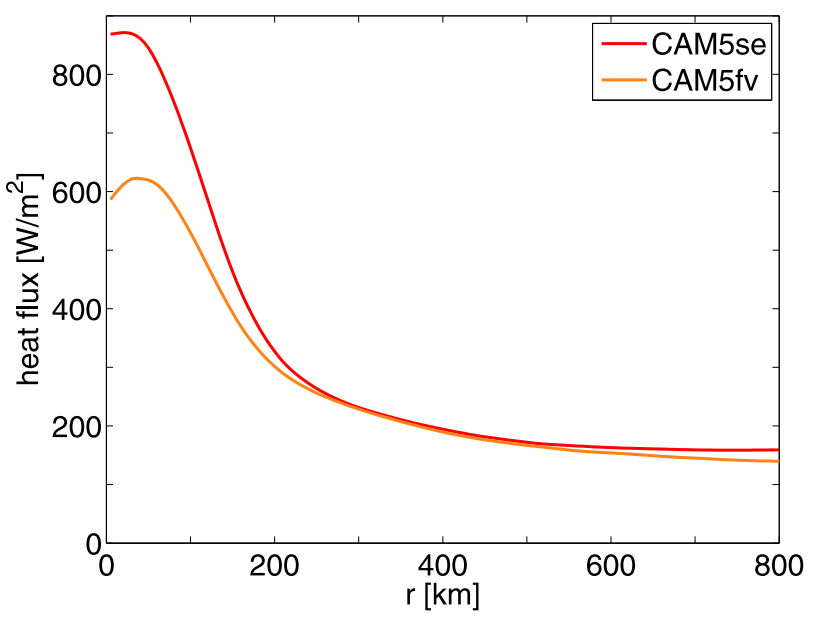

(c) sfc. wind speed 1996-7 TCs @ 30-33 m/s

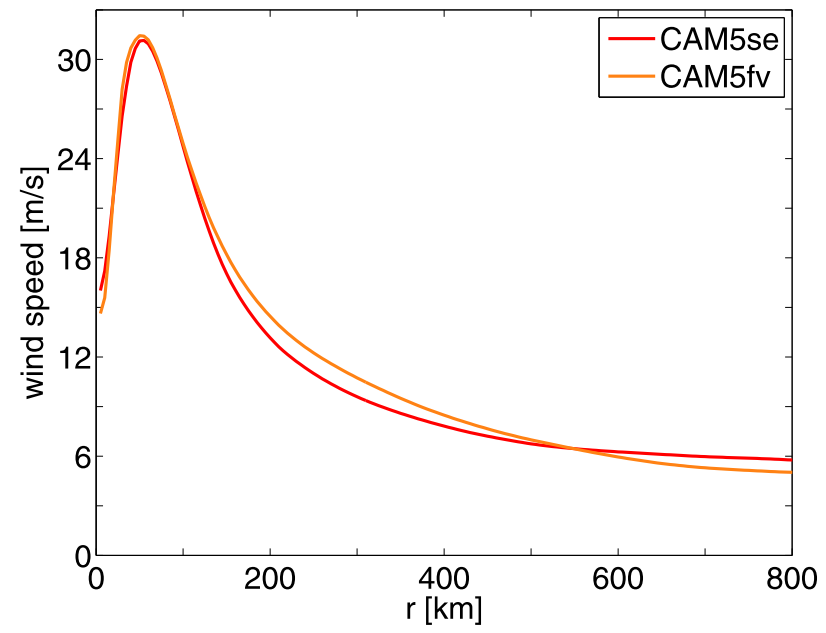

(b) latent heat flux 1996-7 TCs @ 30-33 m/s

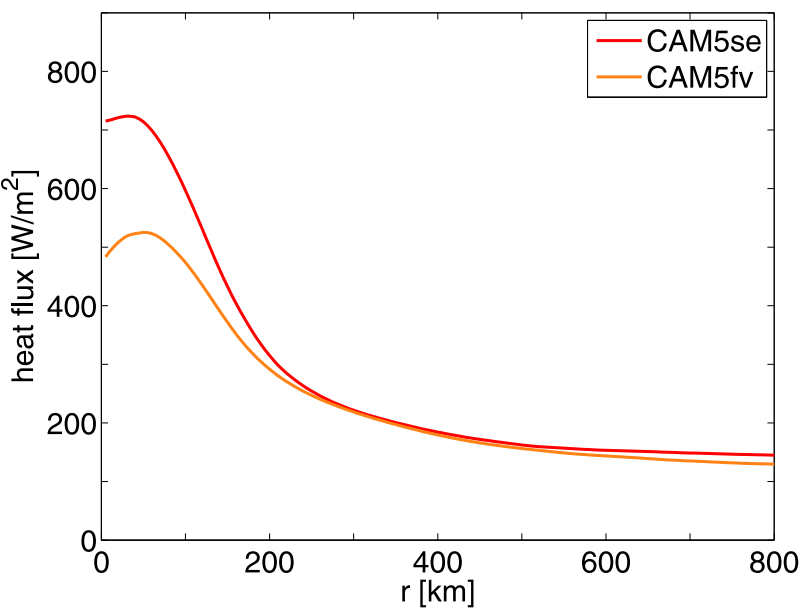

(d) air-sea diff. 1996-7 TCs @ 30-33 m/s

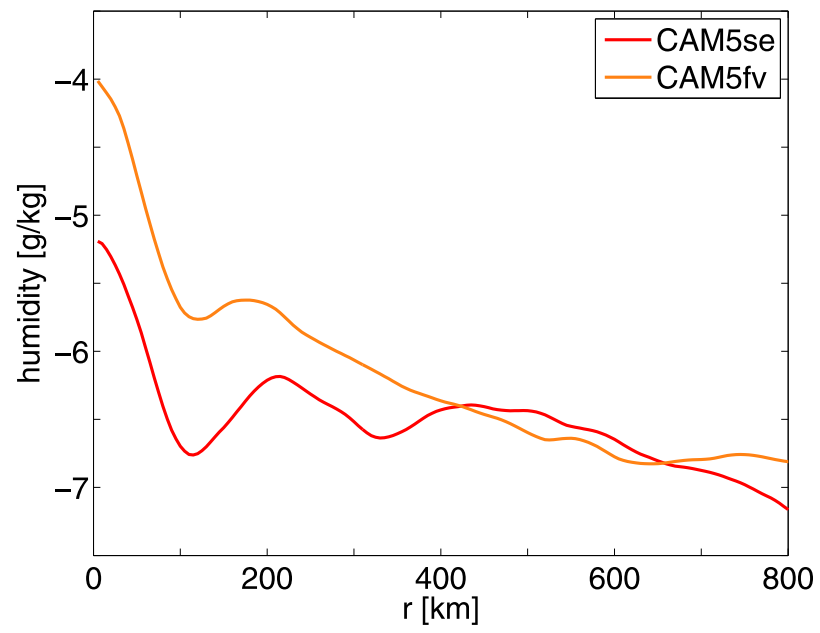

FIG. 14. Azimuthally averaged (a) total surface heat flux, (b) latent heat flux, (c) surface wind speed, and (d) air-sea humidity difference for TC snapshots that have the intensity of $30-33 \mathrm{~m} \mathrm{~s}^{-1}$ for 1996-97 North Atlantic TCs in the CAM5se and CAM5fv simulations.

1982; Shapiro and Willoughby 1982; Hack and Schubert 1986; Nolan et al. 2007).

\section{Summary and conclusions}

This study has examined the azimuthally averaged composite wind and thermodynamic structures of TCs and their sensitivities to horizontal grid spacing in an opportunity-based multimodel ensemble of eight GCM simulations with horizontal resolutions between $0.25^{\circ}$ and $1^{\circ}$. Our analysis indicates that the wind structures in the inner-core regions of TCs are more strongly constrained by horizontal resolutions of the models than are their thermodynamics structures. The azimuthally averaged three-dimensional wind fields show cyclonic swirling circulations with in-up-out secondary circulations that are qualitatively consistent with TC observations. Increased horizontal resolution leads to smaller and more realistic RMWs (thus more compact inner-core structures), but the RMWs are still too large in comparison to the observations, especially when TCs are at greater intensity. Decreasing horizontal grid spacing moves the peak eyewall updrafts radially outward from the center, but there are still rising motions occurring at the center in the composites.

The distributions of precipitation, surface and radiative fluxes, and column moisture around TCs do not exhibit any significant systematic variations with increasing horizontal resolution, except in those that are strongly controlled by the locations of the RMWs and peak rising motions near the center, such as the innercore rainfall structures and the location of the peak surface heat flux. They remained diverse across the models with comparable horizontal resolutions. This 


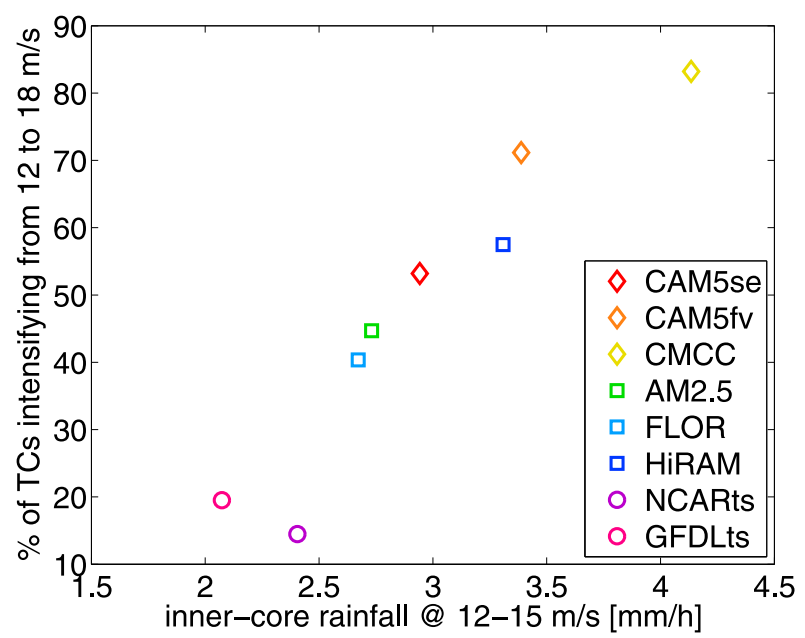

FIG. 15. Scatterplot of the area-averaged inner-core rainfall rates at $12-15 \mathrm{~m} \mathrm{~s}^{-1}$ vs the fraction of TCs intensifying from 12 to $18 \mathrm{~m} \mathrm{~s}^{-1}$ in all simulations. The inner-core region is defined to be 2 times the 850-hPa RMW. Diamonds, squares, and circles are for the $0.25^{\circ}, 0.5^{\circ}$, and $1^{\circ}$ simulations, respectively.

suggests that thermodynamic structures of TCs could be partly responsible for the intermodel diversity of TC intensity in GCM simulations.

The magnitudes of the surface heat fluxes in the simulated TCs are greater than those of the net column radiative flux convergence, but the radial gradient of the net column radiative flux convergence is comparable to that of surface turbulent heat flux for weak TCs, highlighting the importance of cloud-radiative feedbacks during the early developmental phases of TCs. This is consistent with Wing et al. (2016, 2019), who performed a moist static energy variance budget analysis of TC formation and intensification, in which the surface heat flux and net column radiative flux convergence are two of the budget terms. Models that produce greater rainfall in the inner-core regions tended to simulate stronger TCs more frequently, as in Kim et al. (2018), which are consistent with previous theoretical studies. This relationship was noted across almost all of the simulations examined in this study.

It is likely that model attributes other than horizontal resolution-such as convection parameterization schemes-also exert influence on GCM-simulated TC structures. To fully understand TC structures that are simulated differently by different models, it is necessary to evaluate the roles of all model configurations. The focus of the current study is to examine whether and how much of the differences in simulated TC structures could be attributed to differences in the horizontal resolution of the models alone with an opportunity-based multimodel ensemble. We plan on investigating the roles of many other important model attributes on GCM-simulated TC structures in a future study.

This study has made comparisons mostly among GCMsimulated TCs, so it was difficult to determine which GCMs produce more realistic TCs than others without quantifying the degree of the bias in GCM-simulated TC structures against the observations. Efforts are under way to construct an observation-based TC reference state, against which fair GCM TC evaluations can be performed, as similarly done by Gao et al. (2019).

Acknowledgments. This study was supported by the Modeling, Analysis, Predictions, and Projections (MAPP) program of the NOAA Climate Program Office (CPO) through Grants NA15OAR4310087, NA15OAR4310095, NA18OAR4310270, NA18OAR4310276, and NA18OAR4310277. This work is a contribution to the process-oriented diagnostics efforts of the NOAA MAPP Model Diagnostics Task Force (e.g., Maloney et al. 2019). Author Y. Moon was supported in part by an NSF AGS Postdoctoral Research Fellowship (AGS-1524270). Author D. Kim was also supported by the National Aeronautics and Space Administration's Modeling, Analysis, and Prediction program under Grant 80NSSC17K0227, the U.S. Department of Energy's Regional and Global Model Analysis program under Grant DE-SC0016223, and the Korean Meteorological Administration Research and Development Program under Grant KMI2018-03110. We thank Kun Gao, Dasol Kim, and three anonymous reviewers for constructive comments and suggestions.

\section{REFERENCES}

Anthes, R. A., 1982: Tropical Cyclones: Their Evolution, Structure and Effects. Meteor. Monogr., No. 41, Amer. Meteor. Soc., 208 pp.

Bengtsson, L., H. Böttger, and M. Kanamitsu, 1982: Simulation of hurricane-type vortices in a general circulation model. Tellus, 34, 440-457, https://doi.org/10.3402/tellusa.v34i5.10830.

— M. Botzet, and M. Esch, 1995: Hurricane-type vortices in a general circulation model. Tellus, 47A, 175-196, https:// doi.org/10.3402/tellusa.v47i2.11500.

- K. I. Hodges, M. Esch, N. Keenlyside, L. Kornblueh, J. Luo, and T. Yamagata, 2007: How may tropical cyclones change in a warmer climate? Tellus, 59A, 539-561, https://doi.org/ 10.1111/j.1600-0870.2007.00251.x.

Bretherton, C. S., and S. Park, 2009: A new moist turbulence parameterization in the Community Atmosphere Model. J. Climate, 22, 3422-3448, https://doi.org/10.1175/2008JCLI2556.1.

_ J. R. McCaa, and H. Grenier, 2004: A new parameterization for shallow cumulus convection and its application to marine subtropical cloud-topped boundary layers. Part I: Description and 1D results. Mon. Wea. Rev., 132, 864-882, https://doi.org/ 10.1175/1520-0493(2004)132<0864:ANPFSC >2.0.CO;2.

Broccoli, A. J., and S. Manabe, 1990: Can existing climate models be used to study anthropogenic changes in tropical cyclone climate? Geophys. Res. Lett., 17, 1917-1920, https://doi.org/ 10.1029/GL017i011p01917. 
Camargo, S. J., and S. E. Zebiak, 2002: Improving the detection and tracking of tropical cyclones in atmospheric general circulation models. Wea. Forecasting, 17, 1152-1162, https://doi.org/ 10.1175/1520-0434(2002)017<1152:ITDATO>2.0.CO;2.

, and A. H. Sobel, 2004: Formation of tropical storms in an atmospheric general circulation model. Tellus, 56A, 56-67, https://doi.org/10.1111/j.1600-0870.2004.00033.x.

_ , and A. A. Wing, 2016: Tropical cyclones in climate models. Wiley Interdiscip. Rev.: Climate Change, 7, 211-237, https:// doi.org/10.1002/wcc.373.

— A. H. Sobel, A. Barnston, and K. A. Emanuel, 2007: Tropical cyclone genesis potential index in climate models. Tellus, 59A, 428-443, https://doi.org/10.1111/j.1600-0870.2007.00238.x.

Caron, L. P., C. G. Jones, and K. Winger, 2011: Impact of resolution and downscaling technique in simulating recent Atlantic tropical cyclone activity. Climate Dyn., 37, 869-892, https:// doi.org/10.1007/s00382-010-0846-7.

Charney, J. G., 1963: A note on large-scale motions in the tropics. J. Atmos. Sci., 20, 607-609, https://doi.org/10.1175/15200469(1963)020<0607:ANOLSM > 2.0.CO;2.

Chavas, D. R., K. A. Reed, and J. A. Knaff, 2017: Physical understanding of the tropical cyclone wind-pressure relationship. Nat. Commun., 8, 1360, https://doi.org/10.1038/s41467-017-01546-9.

Cherchi, A., and Coauthors, 2019: Global mean climate and main patterns of variability in the CMCC-CM2 coupled model. J. Adv. Model. Earth Syst., 11, 185-209, https://doi.org/ 10.1029/2018MS001369.

Daloz, A. S., and Coauthors, 2015: Cluster analysis of downscaled and explicitly simulated North Atlantic tropical cyclone tracks. J. Climate, 28, 1333-1361, https://doi.org/10.1175/JCLID-13-00646.1.

Delworth, T. L., and Coauthors, 2012: Simulated climate and climate change in the GFDL CM2.5 high-resolution coupled climate model. J. Climate, 25, 2755-2781, https://doi.org/10.1175/JCLID-11-00316.1.

Dennis, J. M., and Coauthors, 2012: CAM-SE: A scalable spectral element dynamical core for the Community Atmosphere Model. Int. J. High Perform. Comput. Appl., 26, 74-89, https:// doi.org/10.1177/1094342011428142.

Emanuel, K. A., 1986: An air-sea interaction theory for tropical cyclones. Part I: Steady-state maintenance. J. Atmos. Sci., 43, 585-605, https://doi.org/10.1175/1520-0469(1986)043<0585: AASITF $>2.0 . \mathrm{CO} ; 2$.

—, 2019: 100 years of progress in tropical cyclone research. $A$ Century of Progress in Atmospheric and Related Sciences: Celebrating the American Meteorological Society Centennial, Meteor. Monogr., No. 59, Amer. Meteor. Soc., https://doi.org/ 10.1175/AMSMONOGRAPHS-D-18-0016.1.

Fogli, P. G., and D. Iovino, 2014: CMCC-CESM-NEMO: Toward the new CMCC Earth System Model. CMCC Research Paper 248, 19 pp., https://doi.org/10.2139/ssrn.2603176.

Frank, W. M., 1977: The structure and energetics of the tropical cyclone I. Storm structure. Mon. Wea. Rev., 105, 1119-1135, https://doi.org/10.1175/1520-0493(1977)105<1119:TSAEOT> 2.0.CO;2.

Gao, K., L. Harris, J.-H. Chen, S.-J. Lin, and A. Hazelton, 2019: Improving AGCM hurricane structure with two-way nesting. J. Adv. Model. Earth Syst., 11, 278-292, https://doi.org/ 10.1029/2018MS001359.

Garratt, J. R., 1992: The Atmospheric Boundary Layer. Cambridge University Press, $316 \mathrm{pp}$

Gray, W. M., and D. J. Shea, 1973: The hurricane's inner core region. II. Thermal stability and dynamic characteristics.
J. Atmos. Sci., 30, 1565-1576, https://doi.org/10.1175/15200469(1973)030<1565:THICRI > 2.0.CO;2.

Hack, J. J., and W. H. Schubert, 1986: Nonlinear response of atmospheric vortices to heating by organized cumulus convection. J. Atmos. Sci., 43, 1559-1573, https://doi.org/10.1175/ 1520-0469(1986)043<1559:NROAVT>2.0.CO;2.

Harris, L. M., S. Lin, and C. Tu, 2016: High-resolution climate simulations using GFDL HiRAM with a stretched global grid. J. Climate, 29, 4293-4314, https://doi.org/10.1175/JCLI-D-150389.1.

Horn, M., and Coauthors, 2014: Tracking scheme dependence of simulated tropical cyclone response to idealized climate simulations. J. Climate, 27, 9197-9213, https://doi.org/10.1175/ JCLI-D-14-00200.1.

Hurrell, J. W., J. J. Hack, D. Shea, J. M. Caron, and J. Rosinski, 2008: A new sea surface temperature and sea ice boundary dataset for the Community Atmosphere Model. J. Climate, 21, 5145-5153, https://doi.org/10.1175/2008JCLI2292.1.

Iacono, M. J., J. S. Delamere, E. J. Mlawer, M. W. Shephard, S. A. Clough, and W. D. Collins, 2008: Radiative forcing by longlived greenhouse gases: Calculations with the AER radiative transfer models. J. Geophys. Res., 113, D13103, https://doi.org/ 10.1029/2008JD009944.

Jorgensen, D. F., 1984: Mesoscale and convective-scale characteristics of mature hurricanes. Part I: General observations by research aircraft. J. Atmos. Sci., 41, 1268-1286, https://doi.org/ 10.1175/1520-0469(1984)041<1268:MACSCO > 2.0.CO;2.

Kim, D., A. H. Sobel, A. D. Del Genio, Y. Chen, S. J. Camargo, M. Yao, M. Kelley, and L. Nazarenko, 2012: The tropical subseasonal variability simulated in the NASA GISS general circulation model. J. Climate, 25, 4641-4659, https://doi.org/ 10.1175/JCLI-D-11-00447.1.

- and Coauthors, 2018: Process-oriented diagnosis of tropical cyclones in high-resolution GCMs. J. Climate, 31, 1685-1702, https://doi.org/10.1175/JCLI-D-17-0269.1.

Kimball, S. K., and M. S. Mulekar, 2004: A 15-year climatology of North Atlantic tropical cyclones. Part I: Size parameters. J. Climate, 17, 3555-3575, https://doi.org/10.1175/15200442(2004)017<3555:AYCONA>2.0.CO;2.

Knapp, K. R., M. C. Kruk, D. H. Levinson, H. J. Diamond, and C. J. Neumann, 2010: The International Best Track Archive for Climate Stewardship (IBTrACS). Bull. Amer. Meteor. Soc., 91, 363-376, https://doi.org/10.1175/2009BAMS2755.1.

Li, T., M. Kwon, M. Zhao, J.-S. Kug, J.-J. Luo, and W. Yu, 2010: Global warming shifts Pacific tropical cyclone location. Geophys. Res. Lett., 37, L21804, https://doi.org/10.1029/2010GL045124.

Lim, Y., S. D. Schubert, O. Reale, M. Lee, A. M. Molod, and M. J. Suarez, 2015: Sensitivity of tropical cyclones to parameterized convection in the NASA GEOS-5 model. J. Climate, 28, 551573, https://doi.org/10.1175/JCLI-D-14-00104.1.

Lin, S., 2004: A "vertically Lagrangian" finite-volume dynamical core for global models. Mon. Wea. Rev., 132, 2293-2307, https://doi.org/10.1175/1520-0493(2004)132<2293:AVLFDC> 2.0.CO;2.

Madec, G., and Coauthors, 2008: NEMO ocean engine version 3.0. Institut Pierre-Simon Laplace Rep. 27, 209 pp.

Mallen, K. J., M. T. Montgomery, and B. Wang, 2005: Reexamining the near-core radial structure of the tropical cyclone primary circulation: Implications for vortex resiliency. J. Atmos. Sci., 62, 408-425, https://doi.org/10.1175/JAS-3377.1.

Maloney, E. D., and Coauthors, 2019: Process-oriented evaluation of climate and weather forecasting models. Bull. Amer. Meteor. Soc., 100, 1665-1686, https://doi.org/10.1175/BAMS-D-18-0042.1. 
Manabe, S., J. L. Holloway, and H. M. Stone, 1970: Tropical circulation in a time-integration of a global model of the atmosphere. J. Atmos. Sci., 27, 580-613, https://doi.org/10.1175/ 1520-0469(1970)027<0580:TCIATI $>2.0$.CO;2.

Manganello, J. V., and Coauthors, 2012: Tropical cyclone climatology in a $10-\mathrm{km}$ global atmospheric GCM: Toward weather-resolving climate modeling. J. Climate, 25, 38673893, https://doi.org/10.1175/JCLI-D-11-00346.1.

Mlawer, E. J., S. J. Taubman, P. D. Brown, M. J. Iacono, and S. A. Clough, 1997: Radiative transfer for inhomogeneous atmospheres: RRTM, a validated correlated-k model for the longwave.J. Geophys. Res., 102, 16 663-16 682, https://doi.org/ 10.1029/97JD00237.

Moorthi, S., and M. J. Suarez, 1992: Relaxed Arakawa-Schubert: A parameterization of moist convection for general circulation models. Mon. Wea. Rev., 120, 978-1002, https://doi.org/ 10.1175/1520-0493(1992)120<0978:RASAPO > 2.0.CO;2.

Murakami, H., and M. Sugi, 2010: Effect of model resolution on tropical cyclone climate projections. SOLA, 6, 73-76, https:// doi.org/10.2151/sola.2010-019.

, and Coauthors, 2012a: Future changes in tropical cyclone activity projected by the new high-resolution MRI-AGCM. J. Climate, 25, 3237-3260, https://doi.org/10.1175/JCLI-D-11-00415.1.

— R. Mizuta, and E. Shindo, 2012b: Future changes in tropical cyclone activity projected by multi-physics and multi-SST ensemble experiments using the 60-km-mesh MRI-AGCM. Climate Dyn., 39, 2569-2584, https://doi.org/10.1007/s00382-011-1223-x.

— , and Coauthors, 2015: Simulation and prediction of category 4 and 5 hurricanes in the high-resolution GFDL HiFLOR coupled climate model. J. Climate, 28, 9058-9079, https:// doi.org/10.1175/JCLI-D-15-0216.1.

Neale, R. B., and Coauthors: 2010: Description of the NCAR Community Atmosphere Model (CAM 4.0). NCAR Tech. Note NCAR/TN-485+STR, 212 pp., www.cesm.ucar.edu/ models/ccsm4.0/cam/docs/description/cam4_desc.pdf.

— - and Coauthors: 2012: Description of the NCAR Community Atmosphere Model (CAM 5.0). NCAR Tech. Note NCAR/ TN-486+STR, 274 pp., www.cesm.ucar.edu/models/cesm1.0/ cam/docs/description/cam5_desc.pdf.

, J. Richter, S. Park, P. H. Lauritzen, S. J. Vavrus, P. J. Rasch, and M. Zhang, 2013: The mean climate of the Community Atmosphere Model (CAM4) in forced SST and fully coupled experiments. J. Climate, 26, 5150-5168, https://doi.org/10.1175/ JCLI-D-12-00236.1.

Nolan, D. S., Y. Moon, and D. P. Stern, 2007: Tropical cyclone intensification from asymmetric convection: energetics and efficiency. J. Atmos. Sci., 64, 3377-3405, https://doi.org/10.1175/ JAS3988.1.

Park, S., and C. S. Bretherton, 2009: The University of Washington shallow convection and moist turbulence schemes and their impact on climate simulations with the Community Atmosphere Model. J. Climate, 22, 3449-3469, https://doi.org/10.1175/ 2008JCLI2557.1.

Price, J. F., 1981: Upper ocean response to a hurricane. J. Phys. Oceanogr., 11, 153-175, https://doi.org/10.1175/1520-0485(1981) $011<0153$ :UORTAH $>2.0 . \mathrm{CO} ; 2$.

Putman, W. M., and S.-J. Lin, 2007: Finite-volume transport on various cubed-sphere grids. J. Comput. Phys., 227, 55-78, https://doi.org/10.1016/j.jcp.2007.07.022.

Reed, K. A., and C. Jablonowski, 2011a: Impact of physical parameterizations on idealized tropical cyclones in the Community Atmosphere Model. Geophys. Res. Lett., 38, L04805, https://doi.org/10.1029/2010GL046297.
— and - 2011b: Assessing the uncertainty in tropical cyclone simulations in NCAR's Community Atmosphere Model. J. Adv. Model. Earth Syst., 3, M08002, https://doi.org/10.1029/ 2011MS000076.

- and - 2011c: An analytic vortex initialization technique for idealized tropical cyclone studies in AGCMs. Mon. Wea Rev., 139, 689-710, https://doi.org/10.1175/2010MWR3488.1.

— intermediate complexity: A test case for AGCMs. J. Adv. Model. Earth Syst., 4, M04001, https://doi.org/10.1029/2011MS000099.

_ , and D. R. Chavas, 2015: Uniformly rotating global radiativeconvective equilibrium in the Community Atmosphere Model, version 5. J. Adv. Model. Earth Syst., 7, 1938-1955, https://doi.org/10.1002/2015MS000519.

_ C. C. Jablonowski, and M. A. Taylor, 2012: Tropical cyclones in the spectral element configuration of the Community Atmosphere Model. Atmos. Sci. Lett., 13, 303-310, https:// doi.org/10.1002/asl.399.

_ J. T. Bacmeister, N. A. Rosenbloom, M. F. Wehner, S. C. Bates, P. H. Lauritzen, J. E. Truesdale, and C. Hannay, 2015: Impact of the dynamical core on the direct simulation of tropical cyclones in a high-resolution global model. Geophys. Res. Lett., 42, 3603-3608, https://doi.org/10.1002/2015GL063974.

- - J. J. A. Huff, X. Wu, S. C. Bates, and N. A. Rosenbloom, 2019: Exploring the impact of dust on North Atlantic hurricanes in a high-resolution climate model. Geophys. Res. Lett., 46, 1105-1112, https://doi.org/10.1029/ 2018GL080642.

Roberts, M. J., and Coauthors, 2015: Tropical cyclones in the UPSCALE ensemble of high-resolution global climate models. J. Climate, 28, 574-596, https://doi.org/10.1175/ JCLI-D-14-00131.1.

— , and Coauthors, 2018: The benefits of global high resolution for climate simulation: Process understanding and the enabling of stakeholder decisions at the regional scale. Bull. Amer. Meteor. Soc., 99, 2341-2359, https://doi.org/10.1175/ BAMS-D-15-00320.1.

Schubert, W. H., and J. J. Hack, 1982: Inertial stability and tropical cyclone development. J. Atmos. Sci., 39, 16871697, https://doi.org/10.1175/1520-0469(1982)039<1687: ISATCD $>2.0 . \mathrm{CO} ; 2$.

Scoccimarro, E., P. G. Fogli, K. A. Reed, S. Gualdi, S. Masina, and A. Navarra, 2017: Tropical cyclone interaction with the ocean: The role of high-frequency (subdaily) coupled processes. J. Climate, 30, 145-162, https://doi.org/10.1175/JCLI-D-160292.1.

Shaevitz, D. A., and Coauthors, 2014: Characteristics of tropical cyclones in high-resolution models in the present climate. J. Adv. Model. Earth Syst., 6, 1154-1172, https://doi.org/ 10.1002/2014MS000372.

Shapiro, L. J., and H. E. Willoughby, 1982: The response of balanced hurricanes to local sources of heat and momentum. J. Atmos. Sci., 39, 378-394, https://doi.org/10.1175/15200469(1982)039<0378:TROBHT>2.0.CO;2.

Shea, D. J., and W. M. Gray, 1973: The hurricane's inner core region. I. Symmetric and asymmetric structure. J. Atmos. Sci., 30, 1544-1564, https://doi.org/10.1175/1520-0469(1973) $030<1544$ :THICRI $>2.0$. CO 2 .

Shen, B.-W., R. Atlas, O. Reale, S.-J. Lin, J.-D. Chern, J. Chang, C. Henze, and J.-L. Li, 2006: Hurricane forecasts with a global mesoscale-resolving model: Preliminary results with Hurricane Katrina (2005). Geophys. Res. Lett., 33, L13813, https://doi.org/ 10.1029/2006GL026143. 
Sobel, A. H., J. Nilsson, and L. M. Polvani, 2001: The weak temperature gradient approximation and balanced tropical moisture waves. J. Atmos. Sci., 58, 3650-3665, https://doi.org/ 10.1175/1520-0469(2001)058<3650:TWTGAA $>2.0$. CO;2.

Stan, C., 2012: Is cumulus convection the concertmaster of tropical cyclone activity in the Atlantic? Geophys. Res. Lett., 39, L19716, https://doi.org/10.1029/2012GL053449.

Ullrich, P. A., and C. M. Zarzycki, 2017: TempestExtremes: A framework for scale-insensitive pointwise feature tracking on unstructured grids. Geosci. Model Dev., 10, 1069-1090, https:// doi.org/10.5194/gmd-10-1069-2017.

Vecchi, G. A., and Coauthors, 2014: On the seasonal forecasting of regional tropical cyclone activity. J. Climate, 27, 7994-8016, https://doi.org/10.1175/JCLI-D-14-00158.1.

— , and Coauthors, 2019: Tropical cyclone sensitivities to $\mathrm{CO}_{2}$ doubling: Roles of atmospheric resolution, synoptic variability and background climate changes. Climate Dyn., 53, 59996033, https://doi.org/10.1007/s00382-019-04913-y.

Wehner, M. F., and Coauthors, 2014: The effect of horizontal resolution on simulation quality in the Community Atmospheric Model, CAM5.1. J. Adv. Model. Earth Syst., 6, 980-997, https:// doi.org/10.1002/2013MS000276.

—, Prabhat, K. A. Reed, D. Stone, W. D. Collins, and J. Bacmeister, 2015: Resolution dependence of future tropical cyclone projections of CAM5.1 in the U.S. CLIVAR Hurricane Working Group idealized configurations. J. Climate, 28, 39053925, https://doi.org/10.1175/JCLI-D-14-00311.1.

Willoughby, H. E., and M. E. Rahn, 2004: Parametric representation of the primary hurricane vortex. Part I: Observations and evaluation of the Holland (1980) model. Model. Mon. Wea. Rev., 132, 3033-3048, https://doi.org/10.1175/MWR2831.1.

Wing, A. A., S. J. Camargo, and A. H. Sobel, 2016: Role of radiative-convective feedbacks in spontaneous tropical cyclogenesis in idealized numerical simulations. J. Atmos. Sci., 73, 2633-2642, https://doi.org/10.1175/JAS-D-15-0380.1.

__ and Coauthors, 2019: Moist static energy budget analysis of tropical cyclone intensification in high-resolution climate models. J. Climate, 32, 6071-6095, https://doi.org/10.1175/JCLID-18-0599.1.

Yamada, Y., M. Satoh, M. Sugi, C. Kodama, A. T. Noda, M. Nakano, and T. Nasuno, 2017: Response of tropical cyclone activity and structure to global warming in a high-resolution global nonhydrostatic model. J. Climate, 30, 9703-9724, https://doi.org/10.1175/JCLI-D-17-0068.1.

Zarzycki, C. M., 2016: Tropical cyclone intensity errors associated with lack of two-way ocean coupling in high-resolution global simulations. J. Climate, 29, 8589-8610, https://doi.org/10.1175/ JCLI-D-16-0273.1.

, and C. Jablonowski, 2014: A multidecadal simulation of Atlantic tropical cyclones using a variable-resolution global atmospheric general circulation model. J. Adv. Model. Earth Syst., 6, 805-828, https://doi.org/10.1002/2014MS000352.

- K. A. Reed, J. T. Bacmeister, A. P. Craig, S. C. Bates, and N. A. Rosenbloom, 2016: Impact of surface coupling grids on tropical cyclone extremes in high-resolution atmospheric simulations. Geosci. Model Dev., 9, 779-788, https://doi.org/ 10.5194/gmd-9-779-2016.

_ D. R. Thatcher, and C. Jablonowski, 2017: Objective tropical cyclone extratropical transition detection in high-resolution reanalysis and climate model data. J. Adv. Model. Earth Syst., 9, 130-148, https://doi.org/10.1002/2016MS000775.

Zhang, G. J., and N. A. McFarlane, 1995: Sensitivity of climate simulations to the parameterization of cumulus convection in the Canadian Climate Centre General Circulation Model. Atmos.-Ocean, 33, 407-446, https://doi.org/10.1080/ 07055900.1995 .9649539$.

Zhao, M., I. M. Held, S. Lin, and G. A. Vecchi, 2009: Simulations of global hurricane climatology, interannual variability, and response to global warming using a $50-\mathrm{km}$ resolution GCM. J. Climate, 22, 6653-6678, https://doi.org/10.1175/ 2009JCLI3049.1.

,-- , and 2012: Some counterintuitive dependencies of tropical cyclone frequency on parameters in a GCM. J. Atmos. Sci., 69, 2272-2283, https://doi.org/10.1175/JAS-D-11-0238.1. , and Coauthors, 2018a: The GFDL global atmosphere and land model AM4.0/LM4.0: 1. Simulation characteristics with prescribed SSTs. J. Adv. Model. Earth Syst., 10, 691-734, https://doi.org/10.1002/2017MS001208. , and Coauthors, 2018b: The GFDL global atmosphere and land model AM4.0/LM4.0: 2. Model description, sensitivity studies, and tuning strategies. J. Adv. Model. Earth Syst., 10, 735-769, https://doi.org/10.1002/2017MS001209. 